\title{
Mineral dissolution and precipitation under stress: model formulation and application to metamorphic reactions
}

\author{
Benjamin Malvoisin ${ }^{1,2}$, and L. P. Baumgartner ${ }^{1}$ \\ ${ }^{1}$ Institut des Sciences de la Terre, Université de Lausanne, Lausanne, Switzerland. \\ ${ }^{2}$ Université Grenoble Alpes, CNRS, ISTerre, 38000 Grenoble, France.
}

\section{Key Points:}

- model of reaction by dissolution-precipitation under stress providing new creep laws for pressure solution and replacement reaction

- in the presence of fluid, dissolution-precipitation creep is the dominant deformation mechanism in the Earth's crust

- grain shape preferred orientation can only develop near thermodynamic equilibrium

Corresponding author: Benjamin Malvoisin, benjamin.malvoisin@univ-grenoble-alpes.fr 


\begin{abstract}
Reactions in the Earth's crust occur through a dissolution-precipitation process in the presence of fluid. Dissolution releases aqueous species which are transported to the locus of precipitation. This replacement process generates creep deformation (i.e. dissolutionprecipitation creep) due to volume change during reaction and stress-controlled mass redistribution in the rock. Reaction under stress also modifies the rock microstructure and the pressure record during metamorphism. A quantitative model for dissolution-precipitation creep is developed here by considering both dissolution and precipitation at grain interfaces to simulate replacement reactions under stress. A new creep law is obtained for pressure solution, allowing for the reaction- and the diffusion-controlled cases to be modelled with a single expression. It is extended to replacement reactions by introducing volume change during reaction. Deformation mechanism maps are generated with the new creep law, indicating that, when fluid is present, dissolution-precipitation creep is the dominant deformation mechanism in the Earth's crust. Numerical model reveals that grain shape preferred orientation only develops near thermodynamic equilibrium. This is consistent with measurements of porphyroblasts preferred orientation in rocks from the Nufenen Pass (Switzerland) having experienced prograde metamorphism. Kinetics play a key role on the thermodynamic pressure of metamorphic reaction. Near the equilibrium, reaction is controlled by either $\sigma_{1}$ or $\sigma_{3}$ depending on the total volume change during reaction whereas it is controlled by the mean stress far from the equilibrium.
\end{abstract}

\title{
1 Introduction
}

Stylolites, pressure shadows or flattened pebbles are common observations in the first $15 \mathrm{~km}$ of the Earth's crust (Gratier et al., 2013). They are markers of anisotropic mineral dissolution and mass transfer. Dissolution occurs when fluid is undersaturated with respect to equilibrium. As many mineral solubilities increase with pressure (Eugster \& Baumgartner, 1987; Dolejš \& Manning, 2011), grain-to-grain surfaces under high normal stress can locally dissolve. The dissolved aqueous species then diffuse and precipitate at surfaces under low normal stress. This process of mass transfer called pressure solution induces compaction by creep at large scale (Durney, 1972). In the presence of fluid and at temperature below $500{ }^{\circ} \mathrm{C}$, pressure solution is thought to be the dominant deformation mechanism in Earth's crust (Rutter, 1976; Gratier \& Gamond, 1990). Pressure solution theory is based on the presence at grain contacts of a thin aqueous film to provide the dissolved aqueous species necessary for crystal growth and transmit the normal stress across the grain contact (Rutter, 1976, 1983). The thinner estimates of aqueous film thickness ranges from 1 to $100 \mathrm{~nm}$ (Renard et al., 1997; Dysthe et al., 2002; Desarnaud et al., 2016).

The existing models of pressure solution consider three steps: dissolution at grainto-grain contacts (source), diffusive transport in the thin aqueous film and precipitation in the pore space (sink) (Rutter, 1976; de Meer \& Spiers, 1999; Niemeijer et al., 2002; Gundersen et al., 2002). They predict strain rate as a function of stress, dissolution and precipitation rates, diffusivity and geometrical parameters. Three main diffusive pathway geometries are used (den Brok, 1998): a thin fluid film model with equally spaced grain boundaries, an island model with fluid-filled channels surrounding grains in contact (Raj, 1982), and a micro-cracking model with complex fluid pathways continuously transformed by stress-corrosion at grain boundaries (Gratz, 1991). These geometries play a first-order role on the estimated strain rates (Xia \& Platt, 2017). The pressure solution models proved their efficiency in reproducing observations in natural samples (sedimentary rocks) and in experiments (Gratier et al., 2009; Niemeijer et al., 2002). However, they are not directly applicable to metamorphic or hydrothermal systems since they consider a single phase. Observations in natural samples (A. Putnis \& Austrheim, 2011) and in experiments (C. Putnis et al., 2005; A. Putnis, 2009; Raufaste et al., 2011) indeed indicate that reactions occur through a replacement process in which primary min- 
eral dissolution and secondary mineral precipitation are coupled at the mineral interface. A critical point to model dissolution-precipitation process in metamorphic rocks is thus to allow for precipitation at the stressed grain boundaries.

Structural features such as strain shadow, grain shape preferred orientation (GSPO) and crenulation cleavage provide evidence for the occurrence of dissolution-precipitation creep in metamorphic rocks. They are used to understand how deformation is accommodated from the scale of a single fault or shear zone (Renard et al., 2000; Gratier et al., 2011; McAleer et al., 2017) to the scale of a subduction zone (Shimizu, 1995; Wassmann \& Stöckhert, 2013b; Platt et al., 2018). The acquisition of GSPO during dissolutionprecipitation requires mass redistribution from highly to low stressed surfaces. It was recognized in a variety of rocks including marble (Bestmann et al., 2004), amphibolite (Imon et al., 2004; Stokes et al., 2012), serpentinite (Wassmann et al., 2011; Bial \& Trepmann, 2013) and micaschist (Wassmann \& Stöckhert, 2013a). However, other processes can lead to the acquisition of GSPO (Kretz, 1966; Means \& Paterson, 1966; Willis, 1977; Brady, 1983; Awad et al., 2000). The possible occurrence of all these mechanisms during metamorphism complicates the interpretation of GSPO in rocks and calls for a better understanding of the conditions required to form a GSPO during dissolution-precipitation.

Dissolution and precipitation under stress could play a fundamental role on the thermodynamics of reactions in metamorphic environments. Wheeler $(2014,2018)$ proposes that the reaction pathway followed during reaction by pressure solution does not allow thermodynamic equilibrium in stressed environments to be defined. However, the stability fields of the various mineralogical assemblages can still be determined and the reaction lines can be shifted by several hundreds of MPa under stress. These results are debated in the metamorphic community (Fletcher, 2015; Hobbs \& Ord, 2016; Moulas et al., 2019) and developing a quantitative model able to reproduce the reaction pathway proposed in Wheeler (2014) would help determining the effect of stress on thermodynamic equilibrium.

Here we develop a model for reaction under stress by considering both reaction kinetics and dissolved aqueous species transport. The model allows creep laws for pressure solution and dissolution-precipitation to be determined. These laws give insights into the importance of dissolution-precipitation creep for deformation in the Earth's crust. We also use the model to determine the conditions favouring the acquisition of GSPO during metamorphism and to constrain the pressure controlling the metamorphic reactions observed in natural systems. The model predictions are compared to observations in metasediments from the Nufenen Pass (Swiss Alps).

\section{Modelling replacement under stress}

\subsection{Theoretical framework}

Fluid promotes metamorphic reactions such as the quartz-coesite transition, the albite $=$ jadeite + quartz geobarometer or the eclogitisation of the lower crust. We develop in the following a model to estimate the first-order effect of stress on such reactions. Parameters used in the model are listed in Table 1.

Let us consider a stressed porous rock matrix reacting at constant temperature under the simplified geometry of Figure 1. The elementary unit of the model is a cubic volume initially composed of the reactant mineralogical assemblage engulfed in a porous network. We study the deformation of this elementary unit during mass redistribution and volume change associated with a replacement reaction under stress. The geometry used here allows for calculations at small porosity and simple upscaling with a face-centered cuboid packing. It differs from the face-centered cubic packing of equally sized spherical grains generally used in pressure solution studies (Yasuhara, 2003). This latter cannot be used below a critical porosity of $3.49 \%$ corresponding to the porosity of the densely 
A

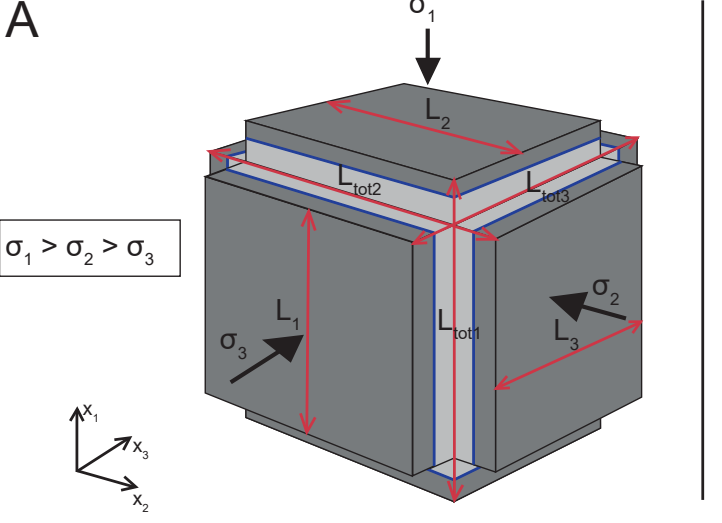

B
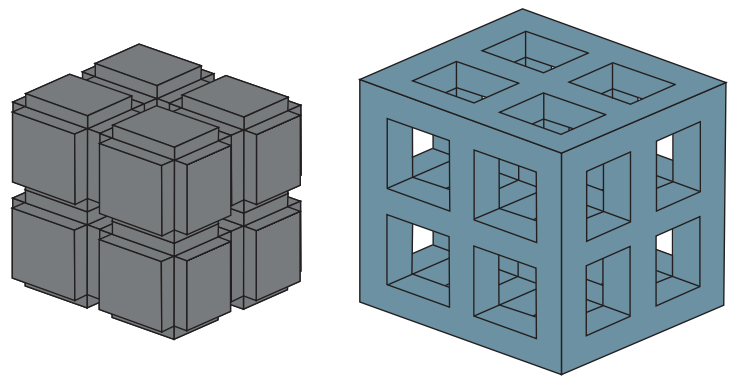

Figure 1. Geometry of the reaction under stress model. A: considered elementary unit. The reacting grain (light grey) is replaced on its stressed surfaces by reaction products (dark grey). The reactants and the products are separated on each face by an aqueous film in which dissolved aqueous species are transported by diffusion (the aqueous films are displayed in blue). Exchanges of dissolved aqueous species between the grain surfaces occur through the porous network occupying the edges and the corners of the cuboid. B: grain packing (left) and associated pore network (right) for an assemblage of 8 cuboids.

packed spheres when the faces of adjacent spheres touch. The fluid in this rock occupies both the pores and the thin films at grain boundaries perpendicular to three stress components ( $\sigma_{\alpha}$ such that $\alpha=1,2$ or 3 ) respecting the following inequality: $\sigma_{1}>\sigma_{2}>$ $\sigma_{3}$. The reference frame is defined by the stress components with coordinate axis vectors, $\overrightarrow{x_{\alpha}}$, parallel to each stress component having the same subscript. The fluid pressure is equal to a constant in the pores $\left(P_{f, 0}\right)$. In the aqueous film, thermodynamic calculations are performed by using the fluid pressure (Dahlen, 1992) which is equal to the normal stress $\sigma_{\alpha}$ (Israelachvili, 1992). This implies that we use a thin film grain boundary model. For simplicity, the fluid pressure in each film is denoted in the following with the stress it is equal to $\left(\sigma_{\alpha}\right)$.

We decompose the replacement reaction in the dissolution and then the precipitation of two different mineralogical assemblages: the initially rock-forming mineral(s) (denoted with subscript $r$ in the following) and the reaction product(s) (denoted with subscript $p$ ). At $P_{f, 0}$, the initially rock-forming minerals are more soluble than the replacing minerals and they will thus dissolve whereas the replacing mineral will precipitate. The aqueous film is considered to be located in between the reacting and produced mineralogical assemblages (Figure 1). The chemical compositions of the reacting and produced mineral assemblages are identical in the model. (De-)volatilization reactions are thus not taken into account here. The involved dissolved aqueous species are identical for the reacting and precipitating phases. We also assume equal transport properties for all the mineral assemblage components in the fluid. This is in line at first-order with the calculations of Oelkers and Helgeson (1988) showing diffusivity of the same order of magnitude for ions in bulk fluid. However, this does not allow to distinguish single minerals in each mineralogical assemblage. Such a level of complexity is considered in Wheeler (1992) and Ford and Wheeler (2004) with more complex geometries involving several grains but it cannot be modelled quantitatively due to the high uncertainty on diffusion coefficients. In summary, the aim here is to provide first-order quantitative estimates for replacement under stress by focusing on mass redistribution in one single cuboid of our model. This requires assuming constant chemical composition in the cuboid, the same 
chemical composition for reactants and products, and the same diffusion coefficients for all the dissolved aqueous species.

For each mineralogical assemblage, the rate of dissolution/precipitation (in mol.s ${ }^{-1}$ ) is modelled under stress $\sigma_{\alpha}$ with the kinetic law of Lasaga (2014):

$$
\begin{aligned}
\dot{\xi}_{\{r, p\}, \alpha} & =k_{\{r, p\}} S_{\{r, p\}, \alpha}\left(1-\exp \frac{-A_{\{r, p\}, \alpha}}{R T}\right)=k_{\{r, p\}} S_{\{r, p\}, \alpha}\left(1-\frac{a_{\alpha}}{a_{e,\{r, p\}, \alpha}}\right) \\
& =k_{\{r, p\}} S_{\{r, p\}, \alpha}\left(1-\frac{c_{\alpha}}{c_{e,\{r, p\}, \alpha}}\right)
\end{aligned}
$$

where $k_{\{r, p\}}$ is a kinetic constant (with unit of mol.m $m^{-2} . s^{-1}$ ), $S_{\{r, p\}, \alpha}$ is the geometrical reactive surface area of the considered mineralogical assemblage in the aqueous film normal to $\sigma_{\alpha}, R$ is the gas constant and $T$ is the temperature. $A_{\{r, p\}, \alpha}$ is the chemical affinity of reaction of dissolution or precipitation under stress $\sigma_{\alpha}$. It is defined at the fluid/solid interface as the difference of the chemical potentials of the minerals under their solid state $\left(\mu_{s,\{r, p\}, \alpha}\right)$ and of the minerals dissolved in the fluid as aqueous species $\left(\mu_{f, \alpha}\right): A_{\{r, p\}, \alpha}=\mu_{s,\{r, p\}, \alpha}-\mu_{f, \alpha} . A_{\{r, p\}, \alpha}$ is first expressed as a function of the activity of the minerals dissolved as aqueous species in the fluid $\left(a_{\alpha}\right)$ and of their activity in the fluid at the equilibrium $\left(a_{e,\{r, p\}, \alpha}\right)$. Then activities are replaced by the concentration of the dissolved minerals $\left(c_{\alpha}\right)$ by assuming that the activity coefficients do not depend on concentration. $c_{e,\{r, p\}, \alpha}$ is the concentration of the dissolving or precipitating phases at the equilibrium under stress $\sigma_{\alpha}$. The composition of the dissolved minerals formed by dissolution or consumed during precipitation are identical. There is thus no need to distinguish the activity (or concentration) of the dissolved minerals between reactants and products, and $a_{\alpha}$ and $c_{\alpha}$ are not mineral-specific.

Dissolved aqueous species migrate in the thin aqueous film as a result of chemical potential gradients between the aqueous film and the pores. The transport of dissolved aqueous species in the planar thin film normal to $\overrightarrow{x_{\alpha}}$ is modelled by diffusion. The release and consumption of aqueous species by dissolution or precipitation, respectively, are modelled with two source terms for dissolution and precipitation occurring at the minerals/fluid interfaces. These terms are obtained by dividing the reaction rate of equation 1 by the volume of the thin aqueous film. We assume here that the reactive surface area of the dissolving and precipitating phases in each fluid film are identical $\left(S_{r, \alpha}=\right.$ $\left.S_{p, \alpha}\right)$ and that the aqueous film thickness $(w)$ is constant so the thin film volume is $S_{p, \alpha} w$. The equation describing the diffusion of dissolved aqueous species and their release/consumption by reaction is finally:

$$
\frac{\partial c_{\alpha}}{\partial t}=D\left(\frac{\partial^{2} c_{\alpha}}{\partial x_{\beta}^{2}}+\frac{\partial^{2} c_{\alpha}}{\partial x_{\gamma}^{2}}\right)+\frac{k_{r}}{w}\left(1-\frac{c_{\alpha}}{c_{e, r, \alpha}}\right)+\frac{k_{p}}{w}\left(1-\frac{c_{\alpha}}{c_{e, p, \alpha}}\right)
$$

where $D$ is the diffusion coefficient of dissolved aqueous species in the aqueous film, $\beta \neq \gamma \neq \alpha=1,2$ or 3 , and the subscript $\alpha$ refers to the normal stress $\sigma_{\alpha}$ at which the concentrations are calculated.

To solve the differential equation 2 , we use as boundary conditions the concentration of dissolved mineral in the pore $\left(c_{0}\right)$. Diffusion in the pore proceeds rapidly compared to diffusion at grain boundaries (Brady, 1983). Therefore, we assume no spatial variations of $c_{0}$. In the following, $c_{0}$ is either fixed by assuming a connection with an infinite source of dissolved aqueous species or calculated by assuming closed system conditions: 


$$
\begin{aligned}
\frac{\partial c_{0}}{\partial t}= & -\frac{4 D w}{V_{0}} \sum_{\alpha=1,2,3 ; \beta \neq \alpha ; \gamma \neq \alpha, \beta}\left(\left.L_{\beta} \frac{\partial c_{\alpha}}{\partial x_{\alpha}}\right|_{b \beta}+\left.L_{\gamma} \frac{\partial c_{\alpha}}{\partial x_{\alpha}}\right|_{b \gamma}\right) \\
& +\frac{k_{r} S_{0, r}}{V_{0}}\left(1-\frac{c_{0}}{c_{e, r, 0}}\right)+\frac{k_{p} S_{0, p}}{V_{0}}\left(1-\frac{c_{0}}{c_{e, p, 0}}\right)
\end{aligned}
$$

where $L$ is the length of the thin film, and the subscript 0 refers to the fluid pressure $P_{f, 0}$ at which the concentrations are calculated. In the geometry used here, each pore is shared between 8 elementary units (Figure 1) and each cuboid summit contains a eight part of a pore. $V_{0}$ is therefore the volume of one pore, and $S_{0, r}$ and $S_{0, p}$ are the reactive surface area in this pore of the reactants and the products, respectively. The two last terms on the right hand side correspond to precipitation/dissolution in the pore. The first term is the Fickian flux of matter from the thin films to the pores at boundaries $b \alpha, b \beta$ and $b \gamma$ parallel to $\overrightarrow{x_{\alpha}}, \overrightarrow{x_{\beta}}$ and $\overrightarrow{x_{\gamma}}$, respectively.

\subsection{Analytical solution in one dimension}

It is instructive to study an analytical solution of equations (2) and (3). The geometry is simplified to recover a solution at steady state in one dimension. The aqueous films are connected to pores in $x=0$ and $x=L$ with $x$ the distance along the aqueous film, so that $c_{\alpha}(x=0)=c_{\alpha}(x=L)=c_{0}$. The composition in the films only varies in one direction (infinitely long sheet-like films in the other direction). The solution of equation 2 at steady state in one dimension is:

$$
c_{\alpha}(x)=c_{b, \alpha}+\left(c_{0}-c_{b, \alpha}\right) \frac{\exp \left(D a_{\alpha} \frac{x}{L}\right)+\exp \left(D a_{\alpha}\left(1-\frac{x}{L}\right)\right)}{1+\exp \left(D a_{\alpha}\right)}
$$

where $c_{b, \alpha}=\frac{k_{r}+k_{p}}{\frac{k_{r}}{c_{e, r, \alpha}}+\frac{k_{p}}{c_{e, p, \alpha}}}$ is the concentration at steady state in the plane normal to $\overrightarrow{x_{\alpha}}$ when diffusion is fast compared to reaction (i.e. the amount of dissolving minerals is exactly balanced by the amount of precipitating minerals). $D a_{\alpha}$ is the Damköhler number defined here as:

$$
D a_{\alpha}=\sqrt{\frac{\left(\frac{k_{r}}{c_{e, r, \alpha}}+\frac{k_{p}}{c_{e, p, \alpha}}\right) L^{2}}{D w}}
$$

$D a_{\alpha}$ compares the timescales of the processes involved in the system, that is reaction and diffusion. It depends on stress as the reaction rates are stress dependent. At high $D a_{\alpha}$, diffusion is slower than reaction and the system is thus controlled by diffusion. Conversely, the system is controlled by reaction at low $D a_{\alpha}$.

Equation 4 reveals that dissolution and precipitation reactions release and consume dissolved aqueous species in order to reach a concentration of $c_{b, \alpha}$ in the aqueous film at which input by dissolution and output by precipitation are exactly balanced. However, this concentration is never reached due to diffusion from or towards the pores in $x=0$ and $x=L$. The direction of diffusive transport depends on the relative values of $c_{0}$ and $c_{b, \alpha}$.

The flux of concentration at boundary $x=0$ can be derived from equation 4 :

$$
\left.\frac{\partial c_{\alpha}}{\partial x}\right|_{x=0}=\left(c_{0}-c_{b, \alpha}\right) \frac{D a_{\alpha}}{L} \frac{1-\exp \left(D a_{\alpha}\right)}{1+\exp \left(D a_{\alpha}\right)}
$$


It is the opposite at boundary $x=L$. This flux can then be introduced into the equivalent of equation 3 in one dimension under the assumptions of steady state to obtain an expression of $c_{0}$ :

$$
c_{0}=\frac{-8 \sum_{\alpha}\left(c_{b, \alpha} D a_{\alpha} \frac{1-\exp D a_{\alpha}}{1+\exp D a_{\alpha}}\right)+c_{b, 0} D a_{0}^{2}}{-8 \sum_{\alpha}\left(D a_{\alpha} \frac{1-\exp D a_{\alpha}}{1+\exp D a_{\alpha}}\right)+D a_{0}^{2}}
$$

where $D a_{0}=\sqrt{\frac{\left(\frac{k_{r}}{c_{e, r, 0}}+\frac{k_{p}}{c_{e, p, 0}}\right) S_{0}}{D w}}$ under the assumption that $S_{0}=S_{0, r}=S_{0, p}$.

It is apparent from equations (4) and (7) that the concentrations are controlled by the Damköhler number, that is by the slowest process between diffusion and surface-controlled kinetics in the pores and in the thin aqueous films. Table 2 gives the borderline cases for $c_{\alpha}$ and $c_{0}$. The variations of $D a_{0}$ compared to $D a_{\alpha}$ are mainly due to differences between the reactive surface area of the pores and the grain boundary, respectively.

\subsection{Expression of strain rate}

Strain rate $\left(\epsilon_{\alpha}\right)$ allows the various deformation mechanisms in the Earth to be compared. As it is usually done in pressure solution studies, we derive in the following strain rates for dissolution-precipitation creep when the system is controlled by diffusion $\left(\dot{\epsilon}_{\alpha D}\right)$ and reaction $\left(\dot{\epsilon}_{\alpha R}\right)$. We also introduce strain rate for a system controlled by volume change during reaction $\left(\dot{\epsilon}_{\alpha V}\right)$, which is specific to replacement reactions. As in most pressure solution studies, strain rate is calculated here as positive when the rock compacts and it is calculated with the solution for mass transfer in one dimension (Gratier et al., 2013). It can be directly recovered from the reaction rates in the thin films:

$$
\dot{\epsilon_{\alpha}}=\frac{2 k_{r} V_{r}}{L}\left(1-\frac{c_{\alpha}}{c_{e, r, \alpha}}\right)+\frac{2 k_{p} V_{p}}{L}\left(1-\frac{c_{\alpha}}{c_{e, p, \alpha}}\right)
$$

where $V_{r}$ and $V_{p}$ are the molar volumes of the replaced and replacing solid phases, respectively. These volumes are involved here since a replacement reaction can induce deformation through volume change. The presence of $L$ in the denominator is related to the distribution of volume change in the considered volume.

At high $D a_{\alpha}$, equation 4 leads to $c_{\alpha}=c_{b, \alpha}$ and equation 8 can thus be re-written as:

$$
\dot{\epsilon_{\alpha V}}=-2 \frac{\Delta_{r} V}{L} k_{m}
$$

where $k_{m}=\frac{k_{r} k_{p}\left(1-\frac{c_{e, p, \alpha}}{c_{e, r, \alpha}}\right)}{k_{r} \frac{c_{e, p, \alpha}}{c_{e} r, \alpha}+k_{p}}$ and $\Delta_{r} V=V_{p}-V_{r}$ are, respectively, the overall reaction rate constant and the solid change in volume for the replacement reaction including both dissolution and precipitation. $\dot{\epsilon}_{\alpha V}$ is thus the strain rate when the system is controlled by volume change during reaction. When the reaction rate is controlled by dissolution, the reaction rate constant of the dissolving phase is smaller than the one of the precipitating phase $\left(k_{r} \ll k_{p}\right)$, and $k_{m}=k_{r}\left(1-\frac{c_{e, p, \alpha}}{c_{e, r, \alpha}}\right)$. When the reaction rate is controlled by precipitation $\left(k_{p} \ll k_{r}\right), k_{m}=-k_{p}\left(1-\frac{c_{e, r, \alpha}}{c_{e, p, \alpha}}\right)$. In the case of isotropic stresses, equation 9 is equivalent to a kinetically-delayed change in solid volume.

$c_{e,\{r, p\}, \alpha}$ depends on stress (Paterson, 1973) as: 


$$
c_{e,\{r, p\}, \alpha}=c_{e,\{r, p\}, 0} \exp \left(\frac{\left(\sigma_{\alpha}-P_{f, 0}\right) V_{\{r, p\}}}{R T}\right)
$$

where $c_{e,\{r, p\}, 0}$ is the concentration of the dissolved or precipitating minerals at the equilibrium at $P_{f, 0}$. We obtain with equations 9 and 10 for $k_{r} \ll k_{p}$ :

$$
\dot{\epsilon_{\alpha V}}=-2 \frac{k_{r} \Delta_{r} V}{L}\left(1-\frac{c_{e, p, 0}}{c_{e, r, 0}} \exp \left(\frac{\left(\sigma_{\alpha}-P_{f, 0}\right) \Delta_{r} V}{R T}\right)\right)
$$

and for $k_{p} \ll k_{r}$ :

$$
\dot{\epsilon}_{\alpha V}=2 \frac{k_{p} \Delta_{r} V}{L}\left(1-\frac{c_{e, r, 0}}{c_{e, p, 0}} \exp \left(-\frac{\left(\sigma_{\alpha}-P_{f, 0}\right) \Delta_{r} V}{R T}\right)\right)
$$

We consider in the following that equilibrium is achieved at $P_{f, 0}\left(c_{e, r, \alpha}=c_{e, p, \alpha}\right.$ when $\left.\sigma_{\alpha}=P_{f, 0}\right)$. By definition, the dissolving assemblage has a higher solubility than the precipitating one $\left(c_{e, r, \alpha}>c_{e, p, \alpha}\right)$. These two latter statements as well as equation 10 imply that $V_{r}<V_{p}\left(\Delta_{r} V>0\right)$ if $\sigma_{\alpha}<P_{f, 0}$. Conversely, $\Delta_{r} V$ is negative when $\sigma_{\alpha}>P_{f, 0}$. As a result, the product $\left(\sigma_{\alpha}-P_{f, 0}\right) \Delta_{r} V$ is always negative in far from the equilibrium conditions and equations 11 and 12 tend towards $-\frac{k_{\{r, p\}} \Delta_{r} V}{L}$ when assuming equilibrium in the pores $c_{e, r, 0}=c_{e, p, 0}$.

Equations 9,11 and 12 are derived at high $D a_{\alpha}$ but they indicate that processes are not controlled by diffusion but rather by volume change during reaction. Studying the diffusion controlled case at high $D a_{\alpha}$ requires assuming no change in volume during reaction, that is $V_{r}=V_{p}$. In these conditions, strain rate can be derived by summing the fluxes of matter at the aqueous film/pore interface and noticing that each mole of exported matter corresponds to a displacement of $\frac{V_{r}}{L^{2}}$ :

$$
\dot{\epsilon_{\alpha}}=\left.8 D \frac{\partial c_{\alpha}}{\partial x}\right|_{x=0} \frac{w V_{r}}{L^{2}}
$$

Equation 13 can then be combined with equation 6 to obtain:

$$
\dot{\epsilon_{\alpha}}=\frac{8 D a_{\alpha} D w V_{r}}{L^{3}}\left(c_{0}-c_{b, \alpha}\right) \frac{1-\exp \left(D a_{\alpha}\right)}{1+\exp \left(D a_{\alpha}\right)}
$$

At $D a_{\alpha}>5, \frac{1-\exp \left(D a_{\alpha}\right)}{1+\exp \left(D a_{\alpha}\right)} \sim-1$ and equation 14 can be simplified to recover the strain rate for a diffusion-controlled system:

$$
\dot{\epsilon}_{\alpha D}=-\frac{8 D a_{\alpha} D w V_{r}}{L^{3}}\left(c_{0}-c_{b, \alpha}\right)
$$

At low $D a_{\alpha}$ (control by reaction), the strain rate can be retrieved from equation 8 by substituting $c_{\alpha}$ with the expression of $c_{0}$ for the different borderline cases (see Table 2).

\subsection{Pressure solution}

Pressure solution models consider only one phase which dissolves at grain contacts. This corresponds to a model proposed here if only considering the reaction of dissolution. There is therefore no replacement reaction and the terms of the previous section with $p$ subscript can all be dropped. Moreover, the geometry is slightly modified since 
the aqueous film needs to be shared between two elementary units. The strain rate of equation 14 needs thus to be divided by 2 .

The strain rate expressed in equation 8 becomes:

$$
\dot{\epsilon_{\alpha}}=\frac{2 k_{r} V_{r}}{L}\left(1-\frac{c_{\alpha}}{c_{e, r, \alpha}}\right)
$$

This latter equation can be re-written with the limits given in Table 2 at low $D a_{\alpha}$ to express the strain rate for a system controlled by reaction:

$$
\dot{\epsilon}_{\alpha R}=\frac{2 k_{r} V_{r}}{L}\left(1-\frac{c_{0}}{c_{e, r, \alpha}}\right)
$$

The consideration of a one phase system also leads to $c_{b, \alpha}=c_{e, r, \alpha}$ which allows equation 14 to be re-written as:

$$
\dot{\epsilon_{\alpha}}=-\frac{4 k_{r} V_{r}}{L}\left(1-\frac{c_{0}}{c_{e, r, \alpha}}\right) \frac{1}{D a_{\alpha}}\left(\frac{1-\exp \left(D a_{\alpha}\right)}{1+\exp \left(D a_{\alpha}\right)}\right)
$$

For a system controlled by diffusion (high $D a_{\alpha}$ ), equation 18 becomes:

$$
\dot{\epsilon_{\alpha D}}=\frac{4 D a_{\alpha} c_{e, r, \alpha} D w V_{r}}{L^{3}}\left(1-\frac{c_{0}}{c_{e, r, \alpha}}\right)
$$

Equations 17 and 19 provide strain rates in the reaction-controlled and diffusioncontrolled cases, respectively. The only unknown is $c_{0}$ in these equations. We determine this unknown under two assumptions (small or large porosity) in the following.

Firstly, at small porosity ( $D a_{0} \ll D a_{\alpha}$; closed system), the concentration in the pores is $c_{0}=\frac{\sum_{\alpha} c_{e, r, \alpha} D a_{\alpha}}{\sum_{\alpha} D a_{\alpha}}$ (Table 2). For non-hydrostatic stresses, grain surfaces normal to $\sigma_{1}$ will dissolve whereas phase precipitation will occur on the grain surfaces normal to $\sigma_{3}$. The rate of this mass transfer at the grain scale can be quantified with equations 17 and 19 .

Secondly, we can assume that pores are connected to a large sink/source of aqueous species buffering the system composition at an equilibrium value of $c_{0}=c_{e, r, 0}$. This is the assumption used in most pressure solution studies when open system conditions are considered. For the reaction-controlled case, combining equation 17 with equation 10 under the assumption $c_{0}=c_{e, r, 0}$ leads to:

$$
\dot{\epsilon}_{\alpha R}=\frac{2 k_{r} V_{r}}{L}\left(1-\exp \left(\frac{-\left(\sigma_{\alpha}-P_{f, 0}\right) V_{r}}{R T}\right)\right) \approx \frac{2 k_{r} V_{r}^{2}\left(\sigma_{\alpha}-P_{f, 0}\right)}{R T L}
$$

When the system is controlled by diffusion (high $D a_{\alpha}$ ) under the assumption of a large aqueous species reservoir, the strain rate is recovered from equation 19 with $c_{0}=$ $c_{e, r, 0}$ :

$$
\dot{\epsilon_{\alpha D}}=-\frac{4 D a_{\alpha} c_{e, r, 0} D w V_{r}}{L^{3}}\left(1-\exp \left(\frac{\left(\sigma_{\alpha}-P_{f, 0}\right) V_{r}}{R T}\right)\right) \approx \frac{4 D a_{\alpha} c_{e, r, 0} D w V_{r}^{2}\left(\sigma_{\alpha}-P_{f, 0}\right)}{R T L^{3}}
$$




\subsection{Deformation mechanism maps}

Equation 18 can be used to generate a deformation mechanism map, allowing pressure solution to be compared with other deformation mechanisms, that is dislocation and diffusion creeps. The parameters needed to plot such a map are the diffusion coefficient, $D$, the reaction rate, $k_{r}$, the aqueous film thickness, $w$, the grain size, $L$, and the concentration at the equilibrium in the aqueous film, $c_{e, r, \alpha}$. Experiments of pressure solution (van Noort et al., 2007, 2011), molecular dynamics simulations (Dysthe et al., 2002) and theoretical studies (Revil, 2001) give estimates of $D$ of $\sim 10^{-10} \mathrm{~m}^{2} . \mathrm{s}^{-1}$, that is one order of magnitude lower than diffusivity in bulk fluid (Oelkers \& Helgeson, 1988). In practice, we use in the following a diffusion coefficient depending on temperature such as:

$$
D=1.2 \cdot 10^{-9} \exp \left(-\frac{10.10^{3}}{R T}\right)
$$

The dependency in temperature in this latter equation is derived from the diffusivity estimates of Oelkers and Helgeson (1988). We use an aqueous film thickness of $w=$ $2 \cdot 10^{-9} \mathrm{~m}$ based on the study of Dysthe et al. (2002). The grain size is fixed to $L=100$ $\mu m . c_{e, r, \alpha}$ is estimated with equation 10 including the aqueous species concentration at the equilibrium at $P_{f 0}\left(c_{e, r, 0}\right)$ calculated with Perple_X (Connolly, 2005) and the merged high pressure databases of Sverjensky et al. (2014) and Holland and Powell (2011) for dissolved aqueous species and solid phases, respectively. $k_{r}$ is poorly constrained since kinetic parameters are generally determined in a bulk fluid with experiments on powders in batch reactors in which the reaction processes are probably strongly different than in an aqueous film. The quartz indentation experiments of Gratier et al. (2009) provide precise strain rate measurements at $350{ }^{\circ} \mathrm{C}$ in a $\mathrm{NaOH}$-bearing fluid and at stress ranging from 25 to $350 \mathrm{MPa}$. Their experimental dataset was fitted with equation 18 to estimate $k_{r}$ (Figure $2 \mathrm{~A}$ ). We obtained a value of $k_{r}=3.10^{-5} \mathrm{~mol} . \mathrm{m}^{-2} \cdot \mathrm{s}^{-1}$ which is four orders of magnitude lower that the rate of quartz dissolution in a bulk fluid estimated with the laws of Tester et al. (1994) and Worley et al. (1996) in the same conditions $\left(k_{r b u l k}\right)$. The experiments of Niemeijer et al. (2002) of quartz grain compaction can also be used to compare $k_{r}$ to the dissolution laws obtained with experiments on powders. They were performed with stresses ranging from 50 to $150 \mathrm{MPa}$ and at temperature comprised between 400 and $600{ }^{\circ} \mathrm{C}$. Estimating stress (and associated reaction progress) at grain contacts from the applied far-field stress in the experiments of Niemeijer et al. (2002) requires introduction of a stress concentration factor $(B)$ (Dewers \& Hajash, 1995) (see details on the calculation in Appendix A). This factor decreases with porosity during compaction as more grain contacts are formed (Figure $2 \mathrm{~B}$ ). Therefore, estimates of reaction rate in the thin aqueous film are more indirect than with the dataset of Gratier et al. (2009). They are at least one order of magnitude lower than in the bulk fluid (Figure $2 \mathrm{~B})$.

The fit of experimental data thus indicate $k_{r}$ values below the one determined in bulk fluid. Since the uncertainty on $k_{r}$ is high ( 1 to 4 orders of magnitude below $k_{r b u l k}$ ), we investigated the influence of this parameter on strain rate prediction by determining two deformation mechanism maps for quartz with either $k_{r}=k_{\text {rbulk }}$ or $k_{r}=k_{r b u l k} /\left(10^{4}\right)$ (Figure $3 \mathrm{C}$ and D). The Damköhler number calculated with equation 5 and the parameters given above are required to plot the deformation mechanism maps. It is displayed in Figure $3 \mathrm{~A}$ and $\mathrm{B}$ for distinguishing between diffusion- and reaction-controlled pressure solution creep. The deformation mechanism maps are obtained by considering, in addition to pressure solution, dislocation and diffusion creeps for which strain rates are calculated with the laws given in Tokle et al. (2019) and Rutter and Brodie (2004), respectively (see Appendix B for details on these laws). . 

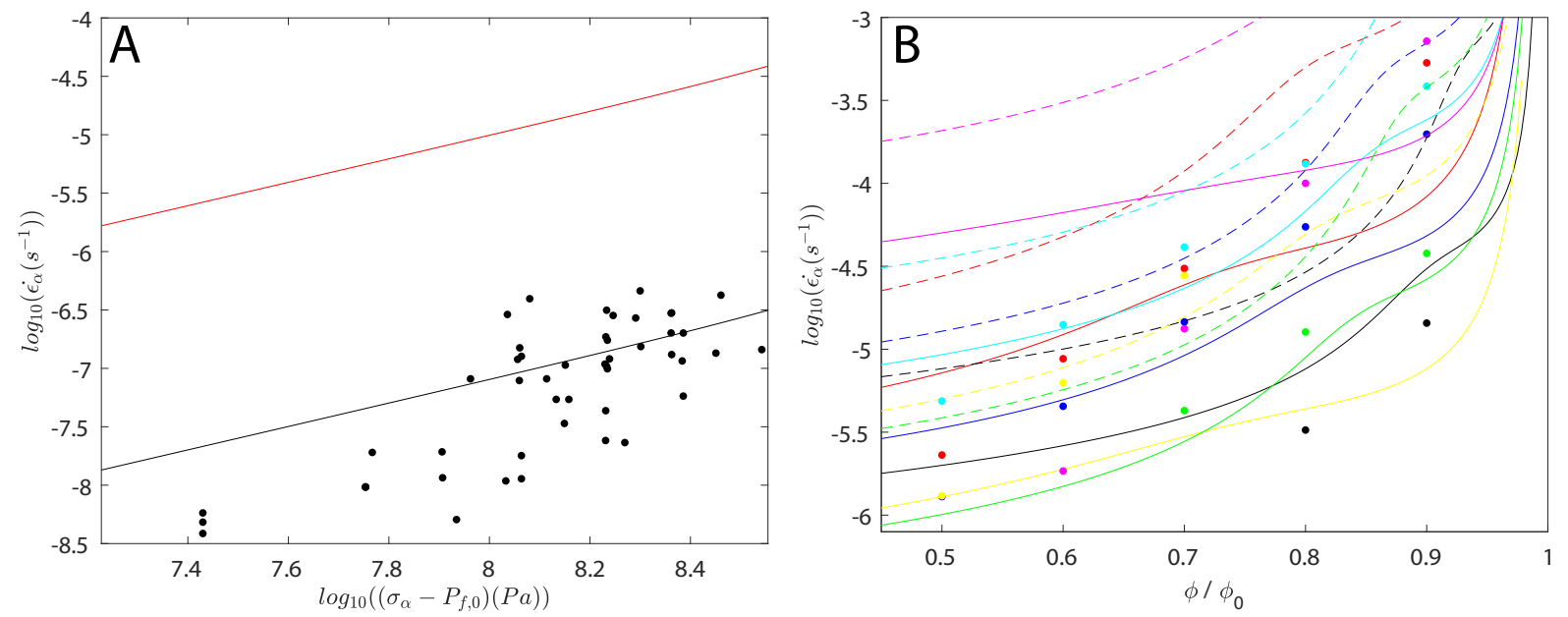

Figure 2. Fit of experimental data with equation 18 to determine $k_{r}$. A: Strain rate as a function of applied normal stress in the quartz indentation experiments of Gratier et al. (2009) (black dots). The black line corresponds to the best fit $\left(k_{r}=2 \cdot 9 \cdot 10^{-5} \mathrm{~mol} \cdot \mathrm{m}^{-2} \cdot \mathrm{s}^{-1}\right)$. The strain rate computed with the reaction rate determined in a bulk fluid $\left(k_{r}=k_{r b u l k}=0.43\right.$ mol. $m^{-2} . s^{-1}$ ) (Tester et al., 1994; Worley et al., 1996) is also displayed with a red line. $k_{r}$ deduced from the fit of the experimental data is four of magnitude lower than $k_{r b u l k}$. B: Strain rate as a function of the ratio between actual and initial porosities $\left(\phi / \phi_{0}\right)$. The data from Niemeijer et al. (2002) are displayed with dots and one colour for each experiment: blue, red, black, yellow, cyan, magenta and green for their experiments CPf3, CPf4, CPf5, CPf6, CPf7, CPf8 and CPf9, respectively. These experiments are performed at different temperature and effective pressure (see Niemeijer et al. (2002) for details). The lines correspond to the best fit of the data for which $k_{r}=k_{r b u l k} / 15$. Dashed lines correspond to the strain rates calculated with $k_{r}=k_{r b u l k}$. The colors of the lines are identical to the color used for the experimental results (dots) when the stress and the temperature used for the computation are identical to those used in the experiments. 
The distribution of the dominant deformation mechanisms is similar for the two reaction rates used for calculating the deformation mechanism maps (Figure 3). Diffusion creep is not a dominant deformation mechanism in the investigated stress-temperature domain. Dislocation creeps dominates at stress above $\sim 10^{8} \mathrm{~Pa}$ and temperature above $\sim 650^{\circ} \mathrm{C}$ whereas pressure solution creep dominates elsewhere. The pressure solution creep domain extends as the reaction rate increases. The strain rate calculated for pressure solution are two orders of magnitude higher when calculated with $k_{r}=k_{\text {rbulk }}$ than with $k_{r}=k_{r b u l k} /\left(10^{4}\right)$, in agreement with equation 18. Pressure solution creep is controlled by reaction at low temperature whereas it is controlled by diffusion at high temperature. The temperature of transition from reaction- to diffusion-controlled pressure solution creep is $\sim 70^{\circ} \mathrm{C}$ and $\sim 350^{\circ} \mathrm{C}$ for $k_{r}=k_{r b u l k}$ and $k_{r}=k_{r b u l k} /\left(10^{4}\right)$, respectively.

The pressure solution model proposed above assumes no precipitation in the aqueous film. This does not allow dissolution-precipitation creep in small porosity rocks to be modelled as it is commonly observed in hydrothermal and metamorphic systems. We use in the following the equations of section 2.2 to extend our understanding of polymineralic assemblages by calculating first-order estimates of strain rate for dissolution-precipitation creep. Such estimates allow to compute deformation mechanism maps including dissolutionprecipitation creep (Figure 4). We consider as an example the metamorphic reaction of muscovite + quartz $<=>$ andalusite + sanidine $+\mathrm{H}_{2} \mathrm{O}$. We assume isotropic stress and small porosity $\left(D a_{0} \rightarrow 0\right)$ so that equation 9 can be used to calculate strain rate at both high and low $D a_{\alpha}$. This strain rate corresponds to the strain rate associated with volume change during reaction $\left(\dot{\epsilon}_{\alpha V}\right)$. The muscovite dehydration involves water exchange between the solid and the fluid phases which is not considered in our model. However, it is one of the few metamorphic reactions for which reaction rates estimates are available as a function of pressure and temperature (Schramke et al., 1987). The use of this reaction as a general kinetic model for metamorphic reactions is justified by the fact that the kinetic data for many metamorphic reactions (including or not volatile species) can be rather accurately fitted with a single rate law (Wood \& Walther, 1983). Calculations are performed by considering that andalusite + sanidine $+\mathrm{H}_{2} \mathrm{O}$ react to produce muscovite + quartz at temperatures lower than the equilibrium whereas the opposite reaction occurs at higher temperature. Equilibrium is thus never achieved in Figure 4 except on the reaction line and reaction rates progressively increase away from this line in agreement with equation 1 . This diagram is therefore only valid if disequilibrium conditions are achieved through changes in composition (e.g. fluid input) or in pressure and/or temperature. We fitted the data of Schramke et al. (1987) with a kinetic law as follows: $k=k_{\text {rbulk }}\left(1-\exp \left(\frac{-A_{t, \alpha, \beta}}{R T}\right)\right)^{n}$ where $k_{\text {rbulk }}=\lambda \exp \left(\frac{-E a}{R T}\right)$ and $A_{t, \alpha, \beta}$ is the distance from the equilibrium defined as the difference between the chemical potential of the dissolving minerals $\left(\mu_{s, r, \alpha}\right)$ and the chemical potential of precipitating minerals $\left(\mu_{s, p, \beta}\right): A_{t, \alpha, \beta}=$ $\mu_{s, r, \alpha}-\mu_{s, p, \beta}$. Two different fits are produced for hydration and dehydration. $k_{r}$ and $k_{p}$ are assumed equal. There are no experimental data for dissolution-precipitation creep which can be used to determine the relationship between $k_{r}$ and $k_{r b u l k}$ as we did for pressure solution. We therefore used the same approach as for pressure solution and plotted deformation mechanism map with $k_{r}=k_{r b u l k}$ and $k_{r}=k_{\text {rbulk }} /\left(10^{4}\right)$ (Figure 4). The concentrations at the equilibrium $\left(c_{e, r, \alpha}\right.$ and $\left.c_{e, p, \alpha}\right)$ are calculated with Perple_X (Connolly, 2005) from the equilibrium constants of muscovite + quartz or andalusite + sanidine $+\mathrm{H}_{2} \mathrm{O}$ dissolution reactions written with $\mathrm{SiO}_{2, a q}, \mathrm{AlO}_{2}^{-}, \mathrm{K}^{+}$and $\mathrm{H}^{+}$as dissolved aqueous species. The molar volumes are $162.68 .10^{-6} \mathrm{~m}^{3} . \mathrm{mol}^{-1}$ and $160.38 .10^{-6}$ $m^{3} \cdot m^{-1}$ for the assemblages muscovite + quartz and andalusite + sanidine, respectively. The Damköhler number calculated with the above parameters for dissolution-precipitation creep is displayed in Figure 4 A and B. It is high in the investigated stress-temperature domain except near the reaction line, where replacement is limited by the reaction rate rather than by diffusion.

Dissolution-precipitation creep is the dominant deformation mechanism in most of the investigated stress-temperature domain even for a low reaction rate $\left(k_{r}=k_{r b u l k} /\left(10^{4}\right)\right.$; 

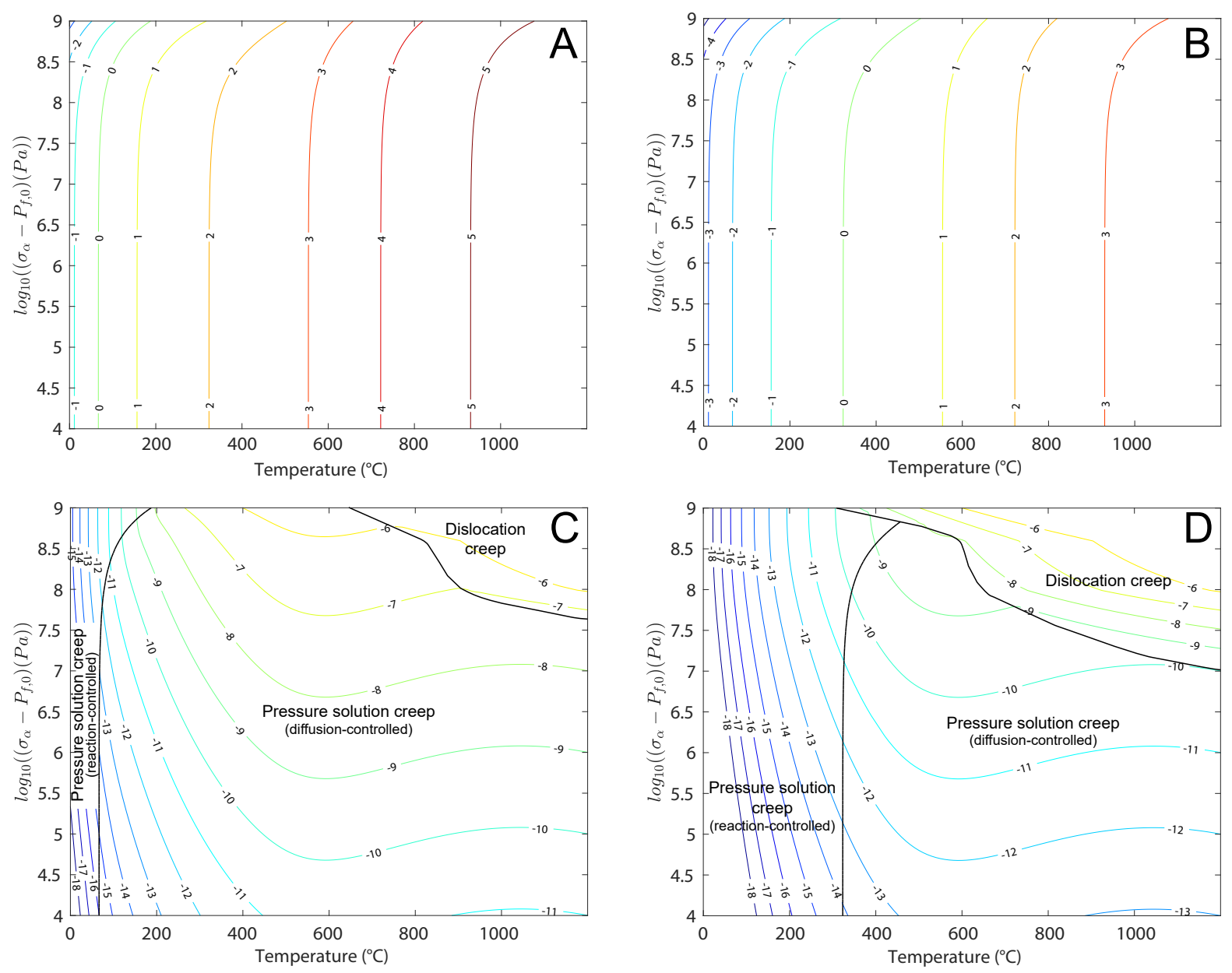

Figure 3. Damköhler number and deformation mechanism maps for quartz as a function of stress and temperature. The calculations are performed with an aqueous film thickness of $w=2 \cdot 10^{-9} \mathrm{~m}$, a grain size of $L=100 \mu \mathrm{m}$, a diffusion coefficient given in equation 22 , and a solubility calculated with equation 10 . Two different reaction rates are used: $k_{r}=k_{r b u l k}$ (A and C) and $k_{r}=k_{r b u l k} /\left(10^{4}\right)(\mathrm{B}$ and D). A and B: calculated Damköhler number. The contours correspond to $\log _{10}\left(D a_{\alpha}\right)$. C and D: deformation mechanism maps. The contours correspond to $\log _{10}(\dot{\epsilon})$. The domains where one of the four studied deformation mechanism (reaction- and diffusion-controlled pressure solution creep, dislocation creep and diffusion creep) dominates are displayed. The strain rates for dislocation and diffusion creeps are calculated with the equations given in Tokle et al. (2019) and Rutter and Brodie (2004), respectively. The strain rate for pressure solution creep is calculated with equation 18. Reaction- and diffusion-controlled domains correspond to $D a_{\alpha}<1$ and $D a_{\alpha}>1$, respectively. 
Figure $4 \mathrm{D})$. The strain rate calculated for dissolution-precipitation creep are four orders of magnitude higher for $k_{r}=k_{\text {rbulk }}$ than for $k_{r}=k_{r b u l k} /\left(10^{4}\right)$, in agreement with equation 9. The calculations do not predict diffusion creep to be a dominant deformation mechanism. The main difference with pressure solution (Figure 3) is observed near thermodynamic equilibrium (i.e. near the reaction line) where dislocation creep can dominate due to the low reaction rate calculated in this region.

\section{Numerical modelling of replacement under stress}

The analytical solutions of the previous sections provide information at first-order on the importance of dissolution-precipitation under stress for deformation. However, they are difficult to directly connect to observations in metamorphic rocks. We develop in the following a numerical model to predict the evolution of grain shape and overall reaction progress during dissolution-precipitation under stress. The numerical model solves equation 2 for the evolution of concentration in three aqueous fluid films of different orientations (normal to $\sigma_{1}, \sigma_{2}$ and $\sigma_{3}$; Figure $5 \mathrm{~A}, \mathrm{~B}$ and $\mathrm{C}$ ). We use the finite difference method with an explicit scheme. The concentration in the pores is computed with equation 3, providing an equation for the boundary conditions. At each time step, we extract the volume of dissolved and precipitated minerals from the evolution of dissolved species concentration. This allows the evolution of grain shape with time to be calculated (Figure $5 \mathrm{D}, \mathrm{E}$ and $\mathrm{F}$ ). The model geometry does not allow different rates in the same aqueous film to be considered. The rates are thus averaged in each film to determine the total volume of dissolving and precipitating minerals. These volumes are then converted into changes in the length of the grain sides by solving for mass conservation with the geometry provided in Figure 1. The simulations conserve mass within less than $1 \%$ after total grain conversion. We use $D=1.7 \cdot 10^{-10} \mathrm{~m}^{2} \cdot \mathrm{s}^{-1}, V_{r}=140 \cdot 10^{-6} \mathrm{~m}^{3} \cdot \mathrm{mol}^{-1}$, $V_{p}=180.10^{-6} \mathrm{~m}^{3} \cdot \mathrm{mol}^{-1}, L=100.10^{-6} \mathrm{~m}, w=2.10^{-9} \mathrm{~m}, \mathrm{c}_{e, r, 0}=0.195 \mathrm{~mol} . \mathrm{m}^{-3}$, $c_{e, p, 0}=0.150 \mathrm{~mol} . \mathrm{m}^{-3}, \sigma_{1}=150 \mathrm{MPa}, \sigma_{2}=100 \mathrm{MPa}$ and $\sigma_{3}=50 \mathrm{MPa}$. The reaction rates $\left(k_{r}\right.$ and $\left.k_{p}\right)$ are equal and varied in-between simulations to investigate different $D a_{\alpha}$.

We first validate the model by reproducing the analytical results presented above. At low $D a_{\alpha}(\sim 0.12)$, the model predicts a constant concentration in the whole system (aqueous films and pores; $c_{\alpha}=c_{0}$ ) which can be approximately calculated with the equation for concentration in the pores derived in one dimension (Table 2; Figure S1 A). The strain rates derived analytically in one dimension at low $D a_{\alpha}$ are also reproduced with a good precision (Equation 8; Figure S1 C). At high $D a_{\alpha}(\sim 380)$, the calculated concentration and strain rates are also approximately equal to the analytical solutions (Table 2 and Equation 9; Figure S1 B and D).

\subsection{Grain shape preferred orientation}

To better understand the acquisition of GSPO during replacement under stress, we numerically investigate the influence of $D a_{\alpha}$ on GSPO by running several simulations with different reaction rates. GSPO is quantified with the aspect ratio calculated after complete replacement and defined as the length of the grain side normal to $\sigma_{3}$ over the length of the grain side normal to $\sigma_{1}\left(\frac{L_{t o t 3}}{L_{t o t 1}}\right)$. At $D a_{\alpha}>100$, the aspect ratio is close to 1 and there is no change in shape during reaction (Figure 6). A strong change in GSPO occurs at $D a_{\alpha}<10$ with an aspect ratio reaching 3.3 at $D a_{\alpha}=0.282$ (Figure 6 ).

\subsection{Pressure controlling the replacement process}

The reaction rate depends on the distance from the equilibrium $\left(A_{t, \alpha, \beta}\right.$; equation $1)$. As the chemical potential depends on pressure, the reaction rates in two differently oriented grain surfaces under different normal stresses are different. Reaction in one of 

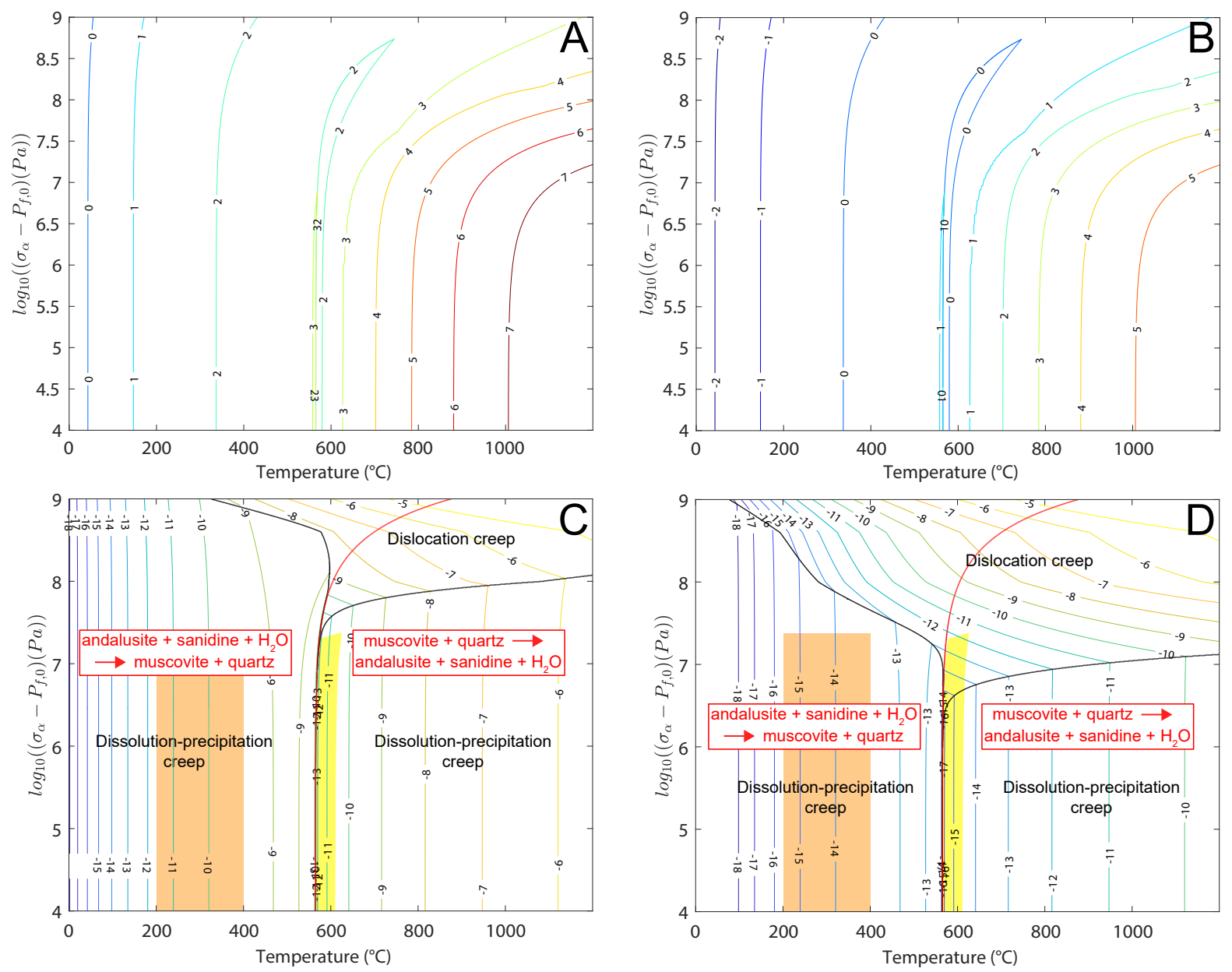

Figure 4. Damköhler number and deformation mechanism map for a system in which the replacement reaction of muscovite + quartz $<=>$ andalusite + sanidine $+\mathrm{H}_{2} \mathrm{O}$ occurs. The calculations are performed with an aqueous film thickness of $w=2.10^{-9} \mathrm{~m}$, a grain size of $L=100 \mu m$, a diffusion coefficient given in equation 22 , and a solubility calculated with equation 10. Two different reaction rates are used: $k_{r}=k_{r b u l k}\left(\mathrm{~A}\right.$ and $\mathrm{C}$ ) and $k_{r}=k_{r b u l k} /\left(10^{4}\right)$ (B and D). A and B: calculated Damköhler number. The contours correspond to $\log _{10}\left(D a_{\alpha}\right)$. C and D: deformation mechanism map. The strain rates for dislocation and diffusion creeps are calculated with the equations given in Tokle et al. (2019) and Rutter and Brodie (2004), respectively. The strain rate for dissolution-precipitation creep is calculated with equation 9 , which is relevant for high $D a_{\alpha}$ and does not depend on differential stress (control by volume change during reaction). The reaction line where equilibrium is reached is shown in red and separates two fields in which we consider either hydration (left) or dehydration (right). The contours correspond to $\log _{10}(\dot{\epsilon})$. The domains where one of the three studied deformation mechanism (dissolution-precipitation, dislocation and diffusion creeps) dominates are displayed. The yellow and orange areas correspond to the regions where prograde metamorphism and hydrothermal conditions are expected to occur, respectively. 


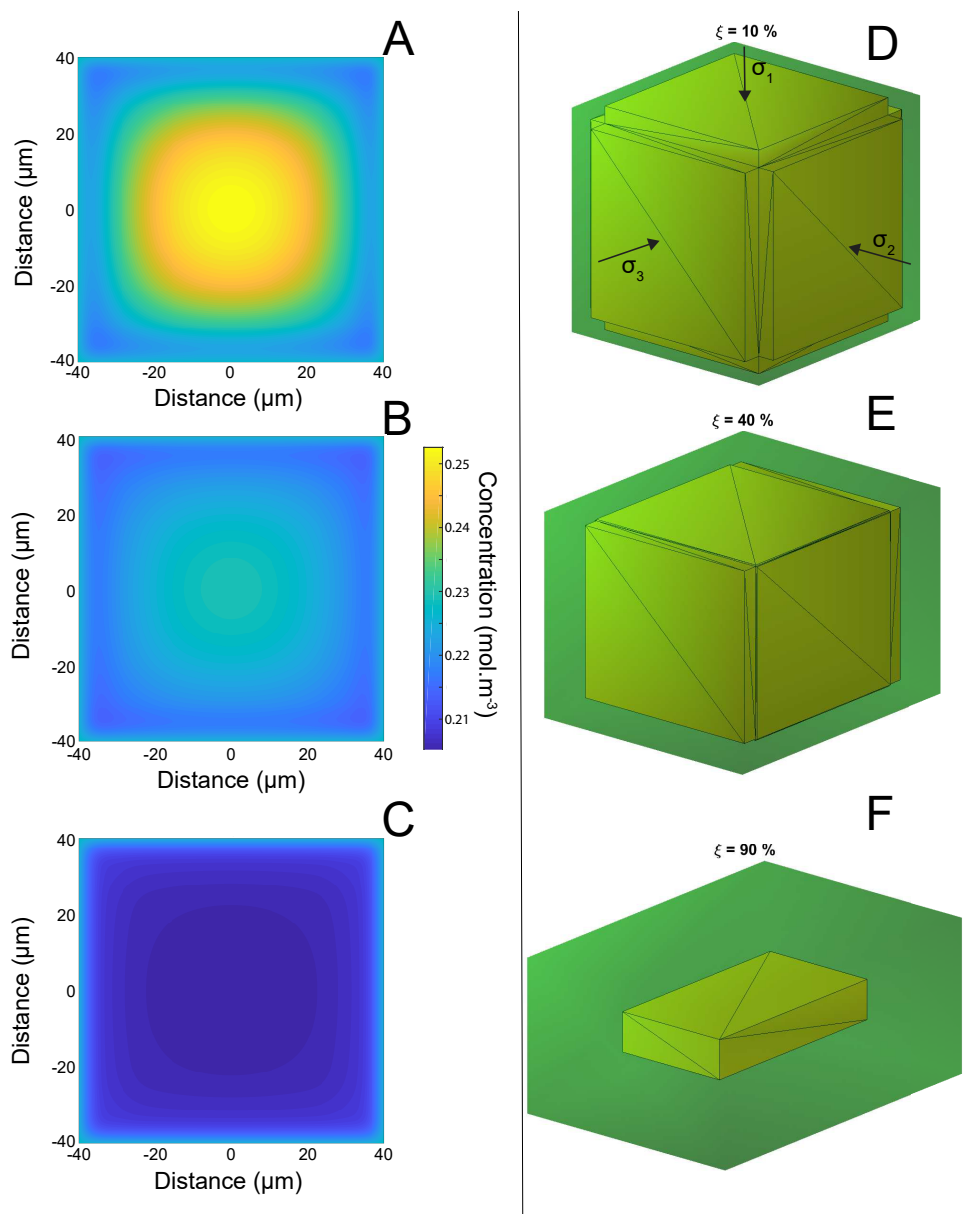

Figure 5. Numerical modelling of replacement reaction under stress for $k_{r}=k_{p}=$ $1.10^{-10}$ mol. $m^{-2} \cdot s^{-1}$. A: concentration in the aqueous film normal to $\sigma_{1}$ at a reaction progress of $\xi=10 \%$. B: concentration in the aqueous film normal to $\sigma_{2}$ at $\xi=10 \%$. C: concentration in the aqueous film normal to $\sigma_{3}$ at $\xi=10 \%$. D: grain shape at $\xi=10 \%$ deduced from reaction rate calculated with the numerical model for concentration in the thin fluid film. The initially rock-forming mineral is displayed in yellow and the reaction products are displayed in green. The orientation of the stress components are indicated. E: grain shape at $\xi=40 \%$. F: grain shape at $\xi=90 \%$. 


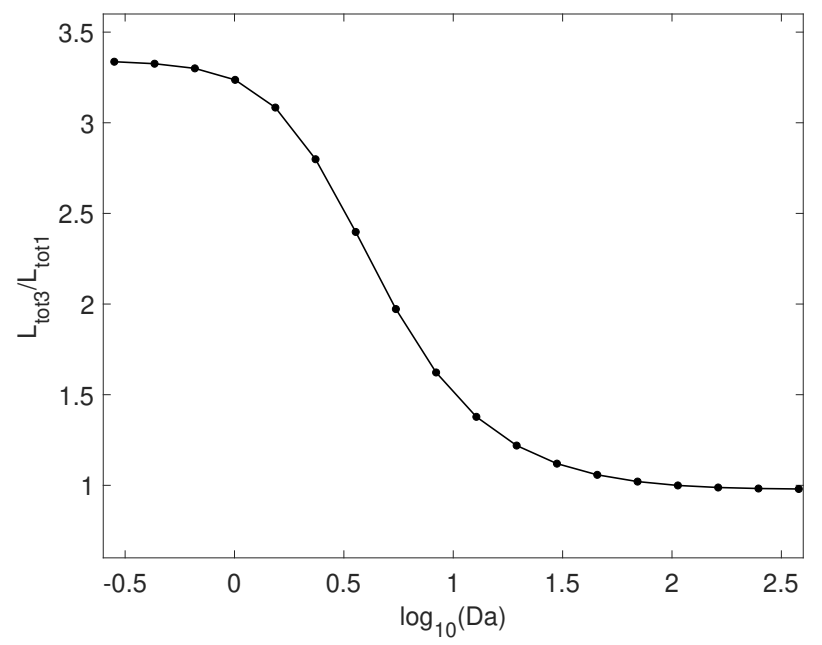

Figure 6. Aspect ratio after complete replacement as a function of the logarithm of $D a_{\alpha}$. The aspect ratio is defined as the length of the grain side normal to $\sigma_{3}$ over the length of the grain side normal to $\sigma_{1}\left(\frac{L_{t o t, 3}}{L_{t o t, 1}}\right)$. Each dot corresponds to one simulation. The differential stress $\left(\sigma_{1}-\sigma_{3}\right)$ is of $100 \mathrm{MPa}\left(\frac{L_{t o t, 3}}{L_{t o t, 1}}\right.$ would be equal to 1 if the grain would grow under isotropic stress).

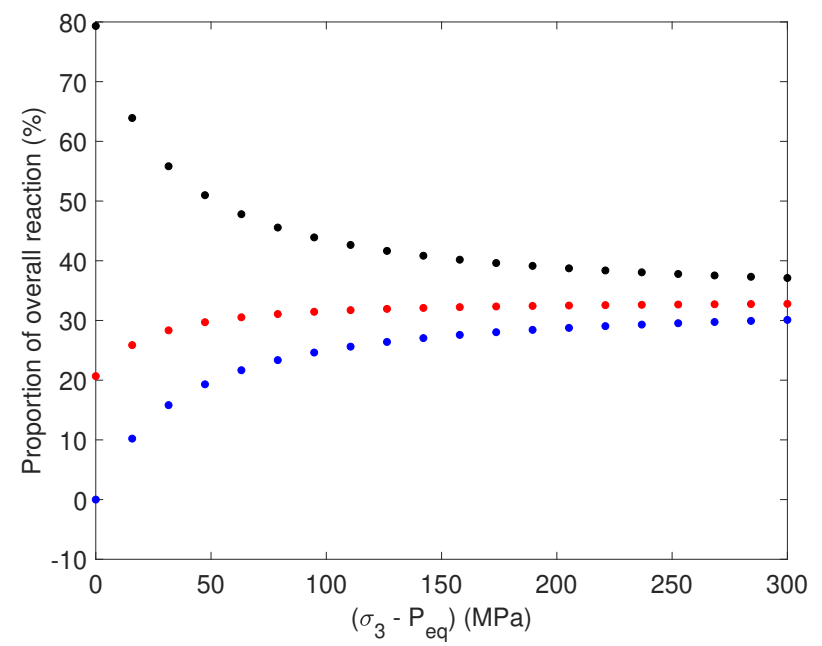

Figure 7. Proportion of the overall reaction progress on each group of mineral faces with the same orientation as a function of the distance from the equilibrium. The faces normal to $\sigma_{1}, \sigma_{2}$ and $\sigma_{3}$ are displayed with black, red and blue dots, respectively. We modify the distance from the equilibrium by increasing the difference between $\sigma_{3}$ and the equilibrium pressure $\left(P_{e q}\right)$. The simulations are performed at high Da with $k_{r}=k_{p}=1.10^{-6}$ mol. $\mathrm{m}^{-2} \cdot \mathrm{s}^{-1}$ and fixed differential stresses $\sigma_{2}-\sigma_{3}$ and $\sigma_{1}-\sigma_{3}$ of 50 and $100 \mathrm{MPa}$, respectively.

the thin aqueous film can thus dominate the replacement process, leading to a control of the reaction by the stress normal to this film.

To quantitatively investigate this process, we run simulations to determine the contribution of each face of the cuboid to the overall reaction progress as a function of the distance from the equilibrium (Figure 7). The distance from the equilibrium increases with pressure in the simulations $\left(A_{t, 1,1}>A_{t, 2,2}>A_{t, 3,3}\right)$. This is equivalent to con- 
sider that the reaction involves a negative change in volume $\left(\Delta_{r} V=V_{p}-V_{r}<0\right.$; left side of the reaction line for a reaction with a positive Clapeyron slope or right side for a reaction with a negative Clapeyron slope). We run several simulations with an increasing difference between $\sigma_{3}$ and the equilibrium pressure $\left(P_{e q}\right)$ while the differential stresses, $\sigma_{2}-\sigma_{3}$ and $\sigma_{1}-\sigma_{3}$, are fixed to 50 and $100 \mathrm{MPa}$, respectively.

At low $D a_{\alpha}$, diffusion proceeds more rapidly than reaction and mass is redistributed between the aqueous films with precipitation which can occur in a different aqueous film than dissolution. The simulations are thus run at $D a_{\alpha}>1$ to be able to isolate the contribution of each face to reaction. Most of grain conversion occurs on the face normal to $\sigma_{1}$ near the equilibrium (Figure 7 ). The pressure controlling reaction is thus $\sigma_{1}$. For reactions with $\Delta_{r} V>0$, the pressure controlling reaction is $\sigma_{3}$. Far from the equilibrium, reaction is equally distributed among the faces (Figure 7) and the thermodynamic pressure is thus the mean stress.

\section{Grain shape preferred orientation in natural samples from the Nufe- nen pass area}

Here we present an application of the model developed above to evaluate GSPO data from a regional metamorphic terrain. The Mesozoic sedimentary cover of the Gotthard massif is well exposed in the Nufenen pass area (Swiss Central Alps). We collected along the road of the Griessee intensively foliated graphite-rich schists. We focused on two different types: one has garnet porphyroblasts (0.6 to $8 \mathrm{~mm}$ in diameter), the other one has plagioclase porphyroblasts ( 1 to $10 \mathrm{~mm}$ diameter). The peak metamorphic conditions were estimated by Klaper and Bucher-Nurminen (1987) and Kamber (1993) at $450-500{ }^{\circ} \mathrm{C}$ and $0.5 \mathrm{GPa}$. In addition to plagioclase and garnet, the rock contains quartz, carbonates, muscovite, biotite, clinozoisite, ilmenite and carbonaceous matter. Garnet and plagioclase are often slightly oval, and visual investigation of the direction of the long axis of the porphyroblasts show that they are not aligned in the pronounced schistosity visible in the field (Figure 8). The schistosity is defined by mica. The stratigraphy, deformation and metamorphism were studied in detail for this area by Liskay-Nagy (1965); Leu (1985); Klaper and Bucher-Nurminen (1987); Kamber (1993). A detailed review of the different nomenclature and tectonic interpretations made by these authors is beyond interest of this study. Nevertheless, we agree with the observations of these authors, that in the profile studied here the peak metamorphic minerals plagioclase and garnet grew after the second folding phase (D2, following the nomenclature of Liskay-Nagy (1965)), which was responsible for the major schistosity in the area. The final deformation phase (D3) did in places result in a rotation of the blasts, visible in a rotation of the schistosity. This was not observed in the samples presented here.

The 3D orientation of the porphyroblasts is determined in seven plagioclase-bearing and six garnet-bearing samples by X-ray microtomography $(\mu \mathrm{cT})$ with a Skyscan 1172 device at the University of Lausanne. Different settings are used for the two types of schists since garnet and plagioclase have higher and comparable X-ray attenuation than the rock matrix, respectively. Garnet-bearing samples were analysed at $130 \mathrm{kV}$ and $60 \mu \mathrm{A}$ with a resolution comprised between 20 and $25 \mu \mathrm{m}$ and a brass filter. Plagioclase-bearing samples are analysed at $70 \mathrm{kV}$ and $114 \mu \mathrm{A}$ with a resolution comprised between 11 and 16 $\mu m$ and an aluminium filter. 3D images are generated from transmission images with the NRecon software. They are then segmented with blob3D (Ketcham, 2005) by considering three phases: the porphyroblast, ilmenite and the matrix. We fit an ellipsoid to each segmented grain to determine the grain aspect ratio (length of the longest axis over length of the shortest axis), the orientations of the main elongation axis and of the main shortening plane. Spherical orientation data are projected in 2D and statistically analysed using Bingham axial distribution with the Stereonet software (Cardozo \& Allmendinger, 2013). Porphyroblasts at the edge of the core and/or coalescing with other grains were excluded from the analysis. Ilmenite grains are elongated in the foliation; 

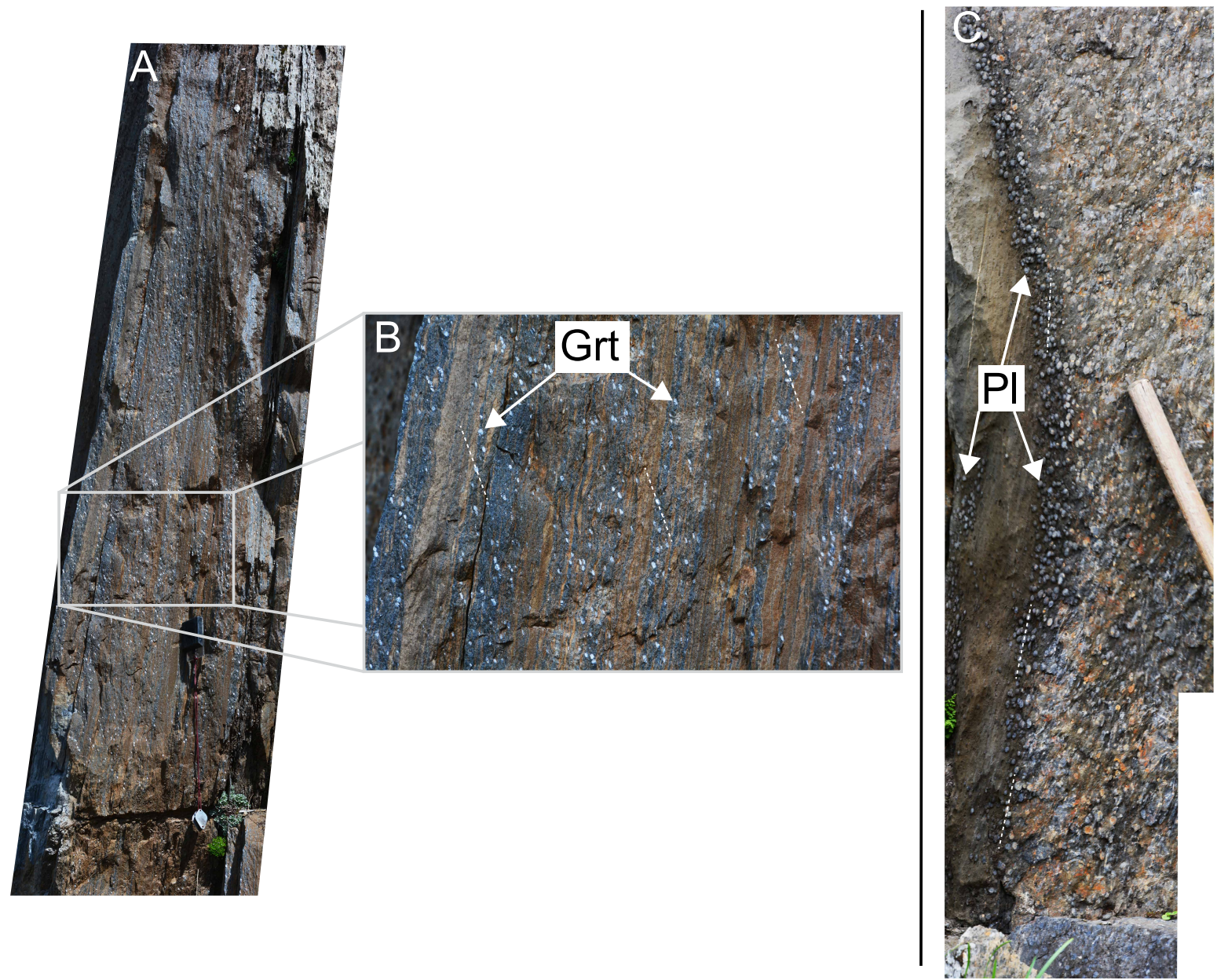

Figure 8. Field pictures of the schists samples at the Nufenen pass. (A) and (B) Garnetporphyroblast (Grt) bearing micaschist. Garnets are more reflective than the surrounding matrix. (C) Plagioclase-porphyroblast (Pl) bearing schist. Plagioclases are mainly form at the lithological contacts. The main elongation axis is displayed with white dashed lines for some porphyroblasts. 
Plagioclase porphyroblast

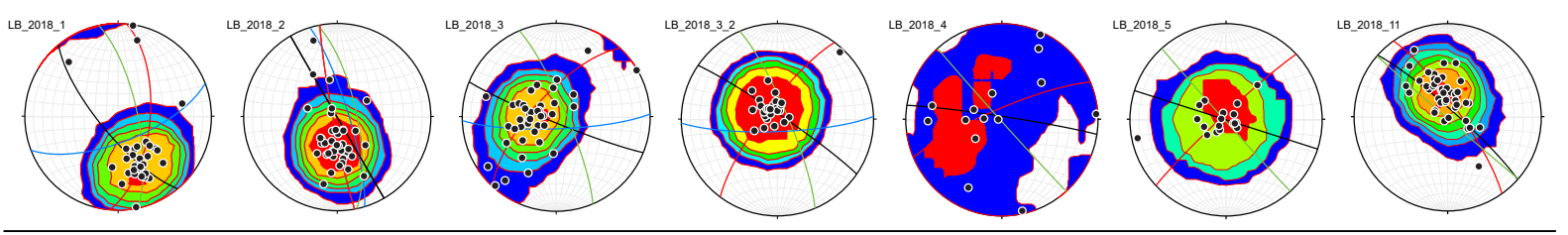

Garnet porphyroblast

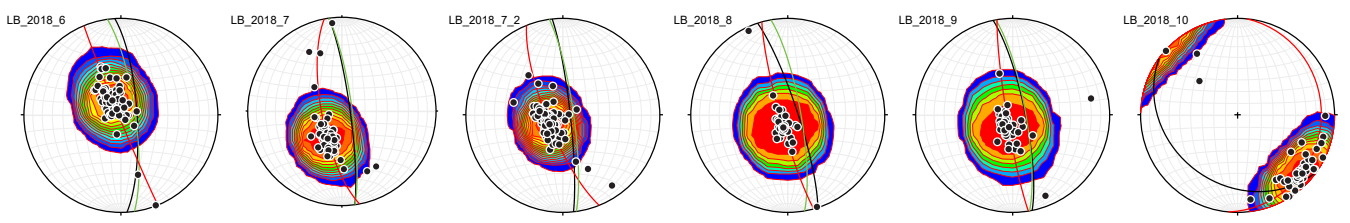

Figure 9. Plagioclase and garnet porphyroblasts orientation for the Nufenen pass area on an equal area lower hemisphere projection. The schistosity measured in the field is in green, the foliation measured with ilmenite orientation in black and the mean porphyroblast shortening plane in red. When the sedimentary layering (S0) is different from the schistosity, it is displayed in blue (samples LB_2018_1, LB_2018_2, LB_2018_3 and LB_2018_3_2). The white dots are the principal elongation axes of the porphyroblasts. The dot density is contoured. Sample LB_2018_10 was not collected in place and orientations are thus given relative to an arbitrary plane chosen as the planar bottom of the core.

their main shortening plane thus gives foliation orientation. The results of statistical analysis are given in Figure 9 and Table 3.

We determine the orientation and the aspect ratio of 13 to 42 plagioclases in 7 different cores and 40 to 96 garnets in 6 different cores (Table 3). Ilmenite crystals outline the orientation of the foliation. This orientation is similar to the schistosity measured in the field for garnet-bearing samples whereas plagioclase-bearing samples collected near a fold hinge display different schistosity and foliation orientations (Table 3 and Figure 9 ). Garnets have an ellipsoidal shape whereas plagioclases are only elongated in one direction (Figure 10). The mean aspect ratios are $2.3 \pm 0.5$ and $1.8 \pm 0.5$ for plagioclase and garnet, respectively (Figure S2). Their elongation axis is oblique to the sedimentary layering (S0) (Figure 9). Plagioclases appear as elongated in the foliation even though the dispersion of the data does not provide a precise estimate of their orientation. Garnets are flattened along a plane oblique to the schistosity/foliation at an angle between 15 and $39^{\circ}$ (Table 3 and Figure 9), confirming the field observations. Garnets contain numerous inclusions of quartz, epidote and ilmenite. These inclusions do not appear to be preferentially elongated (Figure S2). In each core except plagioclase-bearing sample $L B_{-} 2018 \_4$, the orientations of the elongation or of the flattening of the porphyroblasts are similar, indicating a GSPO at the centimetre scale (Table 3). Plagioclase orientation data are more scattered than garnet orientation data at this scale but also at the outcrop scale (Figure 9). Garnet-bearing cores have indeed similar GSPO with a main shortening axis ranging from 158/88 to $169 / 73$ (Azimuth/Dip). The orientation of the main shortening axis of plagioclase varies between $5 / 62$ and 325/80, indicating a variation of the GSPO at the tens of centimetre to the metre scale. These results are in agreement with the observations made in the field, showing that the foliation and the main orientation of plagioclase progressively rotate over a distance of several tens of centimetres (Figure $8 \mathrm{C}$ ). There is no relationship between the main orientation of plagioclases and their aspect ratio. 


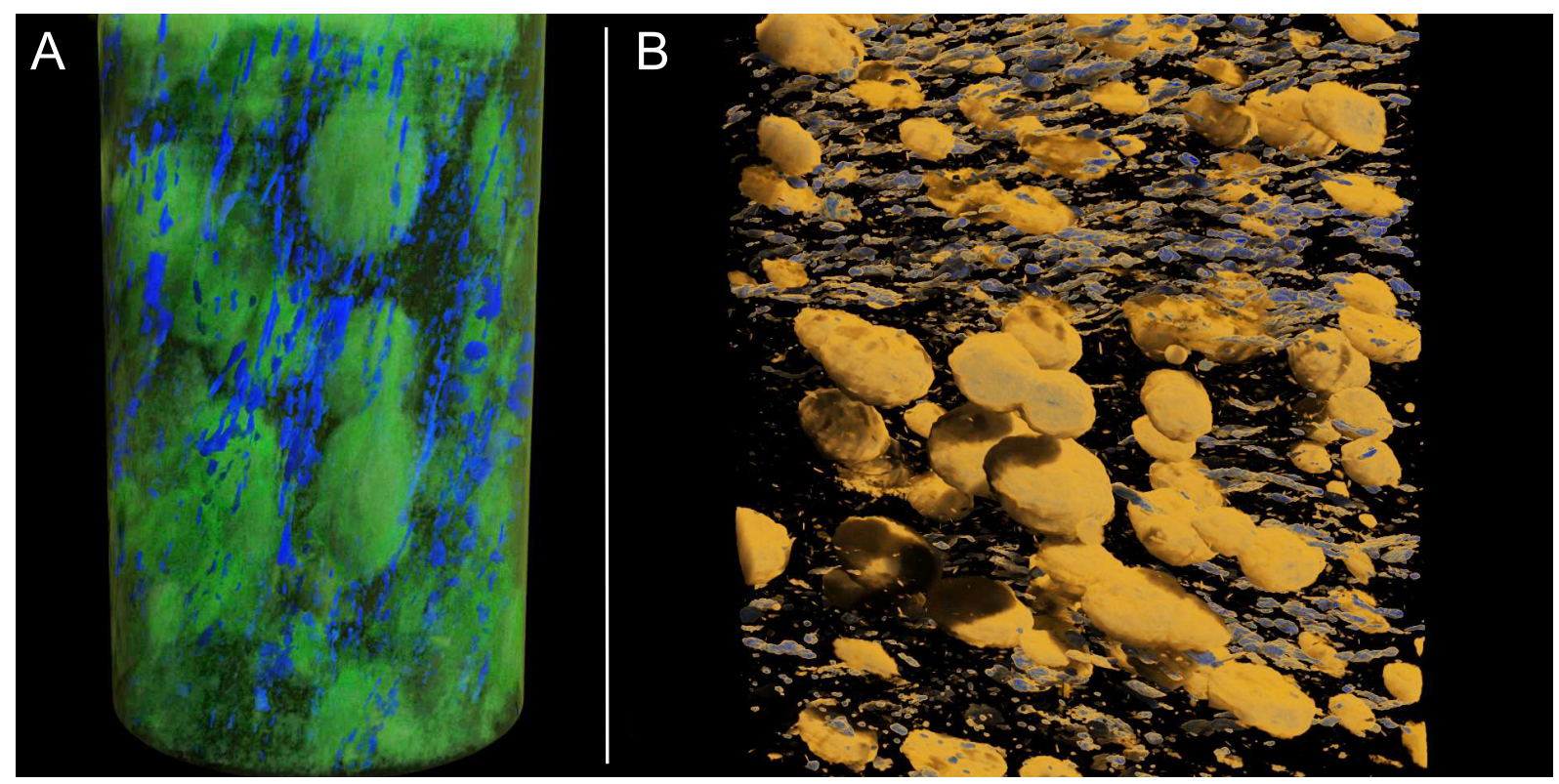

Figure 10. 3D images of segmented cores. A: plagioclase-bearing sample (LB_2018_3_2). B: garnet-bearing sample (LB_2018_6). Garnet, plagioclase and ilmenite are displayed in yellow, green and blue, respectively. The ilmenite crystals serve to determine the orientation of the foliation.

\section{Discussion}

The model proposed here implements two processes which were not considered in the previous models of pressure solution: the possibility for mineral precipitation in the thin aqueous films, that is at grain boundary, and a reaction rate depending on the distance from the equilibrium. These two features lead to new laws for pressure solution and dissolution-precipitation creeps. Moreover, they allow to predict the acquisition of GSPO and to discuss the pressure controlling metamorphic reactions. We discuss in the following the changes brought by these new laws for modelling reaction-driven deformation in the Earth's crust.

\subsection{Comparison with previous creep laws for pressure solution}

Equation 18 is a general creep law for pressure solution. It is obtained by solving for mass transfer in a thin aqueous film in one dimension, like in previous studies on pressure solution (Rutter, 1976; Niemeijer et al., 2002; X. Zhang et al., 2010). The grain size $(L)$ does not evolve during reaction with this approach. Equation 18 is thus only valid if incremental deformation is assumed. Estimating the error associated with this assumption requires to solve for grain shape evolution during dissolution-precipitation. This is done with the numerical model where the strain rate is shown to decrease with time (Figure S1). This decrease is limited to less than one order of magnitude for a reaction progress of less than 0.9. The incremental deformation assumption thus provides valid first-order strain rate estimates for a large range of reaction progresses.

Equation 18 is valid for all $D a_{\alpha}$ values and thus allows strain rate to be calculated in both the reaction- and the diffusion-controlled cases. At low $D a_{\alpha}$ (reaction-controlled regime), equation 18 can be approximated with equation 20 , equivalent, at low stress $\left(\left(\sigma_{\alpha}-P_{f, 0}\right) V_{r} \ll\right.$ $R T)$, to the strain rate determined in reaction-controlled conditions in Raj (1982); Niemeijer et al. (2002); X. Zhang et al. (2010). However, at large stress, equation 20 tends to- 
wards $\frac{k_{r} V_{r}}{L}$. This is consistent with the transition state theory predicting reaction rate independent from the force driving reaction $\left(A_{\{r, p\}, \alpha}\right)$ when $A_{\{r, p\}, \alpha} \gg 0$ (Lasaga, 2014). The expression generally used in the literature for strain rate in the reaction-controlled case (Raj, 1982; Niemeijer et al., 2002; X. Zhang et al., 2010) does not follow the transition state theory since it depends on effective stress as $\left(\exp \left(\frac{\left(\sigma_{\alpha}-P_{f 0}\right) V_{r}}{R T}\right)-1\right)$ and thus tends towards infinity at large stress. For the pressure solution of quartz under a stress of $100 \mathrm{MPa}$, the ratio between the strain rates calculated with the expression found in the literature and with equation 20 is 1.6. This ratio exponentially increases with stress since it is 10 at $500 \mathrm{MPa}$. It could therefore lead to strong change in theoretical estimates especially when stress concentration occurs as it is the case in compacting rock aggregates (Niemeijer et al., 2002).

At high $D a_{\alpha}$ (diffusion-controlled regime), equation 18 can be approximated with equation 21 . This latter equation can be compared to the one generally obtained in pressure solution studies (Rutter, 1976) which can be expressed for the geometry and the formalism used here as (see Appendix $\mathrm{C}$ for a detailed derivation):

$$
\dot{\epsilon_{\alpha S}}=-\frac{24 c_{e, r, 0} D w V_{r}}{L^{3}}\left(1-\exp \left(\frac{\left(\sigma_{\alpha}-P_{f, 0}\right) V_{r}}{R T}\right)\right) \approx \frac{24 c_{e, r, 0} D w V_{r}^{2}\left(\sigma_{\alpha}-P_{f, 0}\right)}{R T L^{3}}
$$

This equation is the same as the one generally used for strain rate in the diffusionlimited case with the exception of the geometric factor 24 associated with the cubic geometry used here (Rutter, 1976; Gratier et al., 2013). Its derivation requires two main assumptions (Appendix $\mathrm{C}$ ): a constant reaction rate and thermodynamic equilibrium in the thin aqueous film (Rutter, 1976). These assumptions may seem contradictory since the driving force for reaction is disequilibrium in the thin aqueous film, and the reaction rate should thus be zero and not a constant at the equilibrium. The assumption of a constant reaction rate leads to a parabolic equation for aqueous species concentration (Appendix C) whereas we derive in equation 4 an hyperbolic cosine function by using a reaction rate depending on the distance from the equilibrium. The assumption of thermodynamic equilibrium in the aqueous film is responsible for the main difference between $\dot{\epsilon_{\alpha D}}$ and $\dot{\epsilon_{\alpha S}}$, that is the absence of the $D a_{\alpha}$ factor in equation 23 compared to equation 21 (Appendix C). The strain rate is underestimated by one order of magnitude at $D a_{\alpha}=100$ with equation 23 compared to equation 21 (Figure 11). The dependency of $\dot{\epsilon_{\alpha} D}$ on $D a_{\alpha}$ indicates that the strain rate depends on reaction rate $\left(k_{r}\right)$ even if the system is controlled by diffusion. An increase in reaction rate indeed leads to a higher dissolved aqueous species concentration in the aqueous film. As the gradient in concentration between the aqueous film and the pores drives diffusion, the transport rate increases leading to a higher strain rate.

The new laws provided here have thus not only different mathematical forms than the previous creep laws but they also lead to orders of magnitude differences in the estimated strain rates. This has to be considered when discussing the importance of pressure solution for deformation in the Earth's crust.

\subsection{Dominant deformation mechanism in the Earth's crust}

Figures $3 \mathrm{C}$ and $\mathrm{D}$ and $4 \mathrm{C}$ and $\mathrm{D}$ provide new deformation mechanism maps including the pressure solution and dissolution-precipitation creep laws determined here. As shown above, these creep laws involve less assumptions than the previous formalisms. Moreover, equation 18 encompasses all $D a_{\alpha}$ values allowing strain rate to be computed without an a priori assumption on the process controlling deformation (diffusion or reaction). Plotting deformation mechanism maps requires quantitative estimates of the parameters used in the creep laws. Significant efforts have been devoted to the determination of the thickness of the aqueous film and the diffusion coefficient (Revil, 2001; Niemei- 


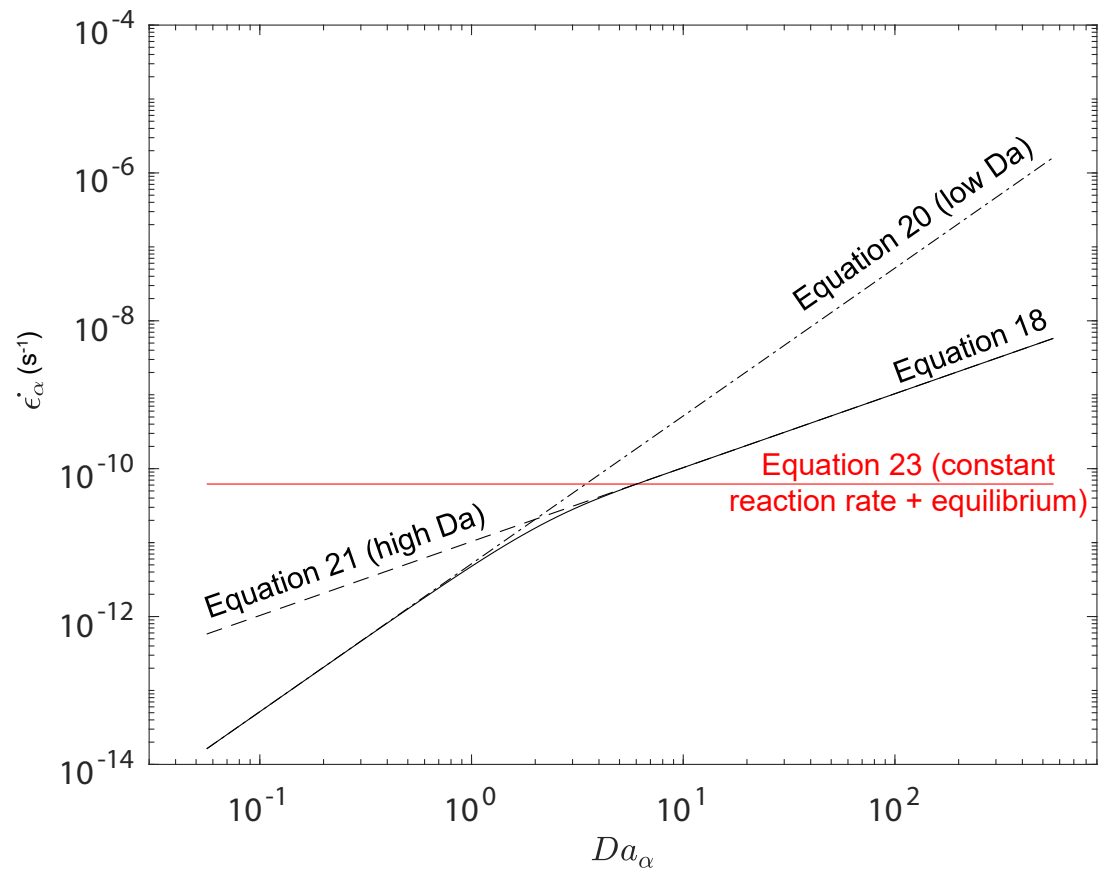

Figure 11. Strain rate as a function of the Dahmköhler number $\left(D a_{\alpha}\right)$ in the aqueous film. The black plain line corresponds to the general expressions for strain rate (equation 18). The black dash-dot and dashed lines are the borderline cases when considering non-constant rates for low $D a_{\alpha}$ (equation 20) and high $D a_{\alpha}$ (equation 21), respectively. The red plain line is the strain rate generally used for diffusion-controlled system. It is derived with constant reaction rate and a condition for thermodynamic equilibrium in the aqueous film (equation 23). The calculations are performed for a typical grain size of $L=100 \mu \mathrm{m}, \sigma_{\alpha}=100 \mathrm{MPa}$, the molar volume of quartz $V_{r}=22 \cdot 10^{-6} \mathrm{~m}^{3} \cdot \mathrm{mol}^{-1}, w=2.10^{-9} \mathrm{~m}, \mathrm{D}=10^{-10} \mathrm{~m}^{2} \cdot \mathrm{s}^{-1}, c_{e, r, 0}=1 \mathrm{~mol} \cdot \mathrm{m}^{-3}$ and $T=573 \mathrm{~K}$. Strain rates are calculated for different $D a_{\alpha}$ by varying $k_{r}$ from $10^{-13}$ to $10^{-5}$ mol.m $\mathrm{m}^{-2} . \mathrm{s}^{-1}$ based on the range given in the works of Tester et al. (1994) and Worley et al. (1996). 
jer et al., 2002; Dysthe et al., 2002; Gratier et al., 2009; van Noort et al., 2007, 2011). However, the reaction rate in the aqueous film, $k_{r}$, is poorly constrained. Previous studies generally assume that the reaction rate determined on unconfined surfaces (bulk fluid) can be used. However, the presence of catalytic dissolved aqueous species (Rimstidt, 2015) or the decrease in water activity (Schott et al., 2009; Lamadrid et al., 2017; Rubie, 1986) can modify the reaction rate in the aqueous film by several orders of magnitude compared to rates measured in bulk fluid. We fit here strain rate data from Niemeijer et al. (2002) and Gratier et al. (2009) with equation 18 to estimate $k_{r}$. The determined values are one to four orders of magnitude lower than the reaction rates measured in the bulk fluid. We therefore plot two deformation mechanism maps for pressure solution (Figure $3 \mathrm{C}$ and $\mathrm{D}$ ) and dissolution-precipitation (Figure $4 \mathrm{C}$ and $\mathrm{D}$ ) with reaction rates equal or four orders of magnitude smaller than the one determined in the bulk fluid. For quartz, the transition from reaction- to diffusion-controlled pressure solution is predicted to occur between $\sim 70{ }^{\circ} \mathrm{C}\left(k_{r}=k_{\text {rbulk }}\right.$; Figure $\left.3 \mathrm{C}\right)$ and $\sim 350{ }^{\circ} \mathrm{C}\left(k_{r}=k_{\text {rbulk }} /\left(10^{4}\right)\right.$; Figure $3 \mathrm{D}$ ). This is consistent with the previous temperature estimate of $\sim 150{ }^{\circ} \mathrm{C}$ for this transition (Gratier et al., 2013). The computed maps indicate orders of magnitude lower strain rates for pressure solution and dissolution-precipitation with $k_{r}=k_{r b u l k} /\left(10^{4}\right)$ than with $k_{r}=k_{\text {rbulk }}$ (Figures $3 \mathrm{C}$ and $4 \mathrm{C}$ ). The distribution of the dominant deformation mechanisms is similar for the two reaction rates. However, it is different from the deformation mechanism map proposed by Rutter (1976) in which diffusion creep dominates at temperatures higher than $\sim 600{ }^{\circ} \mathrm{C}$. The use of equation 18 instead of equation 23 plays a key role in this switch from a map with three possible deformation mechanism to a map where pressure solution dominates. Indeed, recovering with equation 18 a deformation mechanism map similar to Rutter (1976) requires a reaction rate eleven orders of magnitude smaller than the one measured in a bulk fluid $\left(k_{r}=10^{-16} \mathrm{~mol} \cdot \mathrm{m}^{-2} \cdot \mathrm{s}^{-1}\right.$ for quartz at $350{ }^{\circ} \mathrm{C}$ ). Figures 3 and 4 thus provide robust distributions of the deformation mechanisms even though the absolute strain rate values will probably need to be re-evaluated when disposing of better constraints on reaction rate. These maps indicate that pressure solution and dissolution-precipitation creeps are the main deformation mechanisms in the Earth's crust.

One has to keep in mind the limitations of the model when using the deformation mechanism maps. First, we use a simple geometry with all the minerals dissolving or precipitating in the same cuboid, and we consider that dissolved aqueous species are transported at similar rates. We can thus not reproduce the complex distribution of minerals in natural samples, and transport distances can be underestimated by several times the grain size. These are second-order issues regarding uncertainties in quantitative modelling which are mainly due to the variation in reaction rate estimates by several orders of magnitude. Moreover, other models are available to understand mineral distribution or to compare the deformation of monomineralic and polymineralic assemblages (Wheeler, 1992; Ford \& Wheeler, 2004). Mineral distribution can become a first-order process to take into account only if it strongly modifies diffusivity or reaction rate. Greene et al. (2009) measure an increase in quartz dissolution rate when it is in contact with mica rather than with another quartz crystal. The role of sheet minerals is not fully understood but is related to a change in electrical potential. These experimental results are consistent with observations in natural samples showing the activation of pressure solution by the presence of sheet silicates (Heald, 1955; Engelder \& Marshak, 1985). Mineral distribution could thus be a key process to be introduced in further model development but this would require to better capture the physics underlying the catalytic effect of sheet silicates.

Secondly, we assume that free fluid is available in the system during deformation. Fluid is probably not commonly present in the Earth's crust explaining why quartz commonly deforms by dislocation creep in natural settings at temperatures above $300{ }^{\circ} \mathrm{C}$ (Stipp et al., 2002; Trepmann \& Stöckhert, 2003; Kilian et al., 2011). Similarly, diffusion creep is expected to occur at high temperature if fluid availability is low. These observations 
combined with predictions of our model suggest that large sections of the Earth's crust are dry or at least not wet enough to allow for pressure solution. It is critical to estimate the range of fluid content necessary to activate pressure solution. This first requires to better constrain the geometry of the fluid pathways involved in pressure solution. Evidence for dissolution-precipitation creep are mainly collected in metasediments containing hydrous minerals (Stöckhert et al., 1999; Wassmann \& Stöckhert, 2013a; Xia \& Platt, 2017). Fluid availability can be transient for example in metamorphic environments where fluid expelled during dehydration is transported towards the surface (Connolly, 1997; Omlin et al., 2017). Fluid transport mechanisms over several kilometres involve large fluid pathways whereas the stress sustained by the rock can only be transmitted to the fluid in nanometre-size aqueous films (Israelachvili, 1992). High fluid availability may therefore not favour pressure solution but the quantification of this effect requires estimation of pore distribution up to the nanoscale.

Finally, dissolution-precipitation creep is a transient mechanism since it occurs while reaching equilibrium. It thus requires a driving force for reaction which can be a change in temperature, pressure or chemistry.

\subsection{Acquisition of GSPO by dissolution-precipitation creep}

The observation of a GSPO is commonly used as a marker of dissolution-precipitation creep in rocks (Gratier et al., 2013; Wassmann \& Stöckhert, 2013a). The formation of a GSPO requires that minerals form with an anisotropic shape and that the shapes of the grains are orientated similarly. Several mechanisms can lead to a GSPO: 1) the tortuosity is lower for a diffusion path parallel rather than perpendicular to the schistosity leading to an anisotropic growth if the mineral grows by diffusion. The long axis of the crystals is in the schistosity (Brady, 1983); 2) the grain growth kinetics depend on crystallographic orientation (Awad et al., 2000); 3) the interfacial energies at the contact between the growing and the surrounding minerals can systematically vary due to a crystallographic preferred orientation of the surrounding minerals (Kretz, 1966). This leads to a growth preferred orientation inherited from the host mineral or matrix; 4) the grains can rotate and/or plastically elongate for a significant finite strain of the matrix (Willis, 1977; Means \& Paterson, 1966); 5) as demonstrated here with numerical modelling or in experiments (Gratier et al., 2015), dissolution-precipitation under stress can also favour grain shape preferred orientation. A combination of these mechanisms will promote GSPO as shown for example with a positive feedback between pressure solution and crystallographic preferred orientation (Bons \& den Brok, 2000).

We document a pronounced GSPO for garnet and plagioclase in the samples from the Nufenen Pass area with aspect ratios ranging from 1.6 to 2.6 and a similar orientation at the centimetre scale.

Garnet grows isotropically, hence its crystallographic orientation cannot lead to the observed formation of ellipses. Since maximum temperatures never exceeded $500{ }^{\circ} \mathrm{C}$, garnet elongation by plastic deformation is very unlikely (Karato et al., 1995). Moreover, the ellipses are obliquely oriented with respect to the schistosity and they all have a similar orientation (Figures 9 and 10 and Table 3). The variation of the diffusion coefficient (Brady, 1983) and/or of the interfacial energy (Kretz, 1966) with the orientation relative to the schistosity are thus not responsible for the aspect ratios measured here. This suggests a formation after the main foliation event (D2), consistent with the conclusions of Klaper and Bucher-Nurminen (1987) based on textural observations. The most probable mechanism for the acquisition of GSPO is thus growth under stress. Garnet deformation by pressure solution has already been observed in metamorphic rocks (Bell \& Rubenach, 1983; Hara et al., 1984; Bell et al., 1986; Duebendorfer \& Frost, 1988; Álvarez-Valero et al., 2005; Smit et al., 2011; Wassmann \& Stöckhert, 2013a). 
Plagioclase commonly develops a GSPO. The growth and dissolution rates of this mineral depends on crystallographic orientation (Arvidson et al., 2004). However, anisotropic reaction rates are not sufficient to produce a GSPO since the grains also need to have the same orientation at the centimetre scale. GSPO in plagioclase can develop as a result of plastic deformation (Stünitz et al., 2003), at temperature as low as $500{ }^{\circ} \mathrm{C}$ (Shigematsu \& Tanaka, 2000; Rosenberg \& Stünitz, 2003). At low metamorphic grades, plagioclase does not deform by plastic deformation but rather by dissolution-precipitation (Shelley, 1989). The maximum temperature estimate in the Nufenen pass area is $\sim 500{ }^{\circ} \mathrm{C}$ (Kamber, 1993), that is close from the temperature at which plastic deformation can occur in plagioclase. However, there is no evidence for rotation in the studied samples, suggesting that elongation is not associated with plastic deformation. The plagioclases collected in the Nufenen pass area are elongated in the foliation, suggesting that GSPO is acquired during or after the main deformation event D2 (Klaper \& Bucher-Nurminen, 1987). Plagioclases are found in a fold at the contact between a massive carbonate strata and a finely-grained schist (Figure $8 \mathrm{C}$ ). This may explain the variation of the GSPO observed at the outcrop scale due to the refraction of schistosity during D2. As the plagioclases are oriented in the foliation, the mechanism responsible for GSPO acquisition is more difficult to determine than for garnet. It could be mass transfer during a dissolution-precipitation process but also anisotropic diffusion or growth in the foliation. There is no relationship between the orientation of the plagioclases and their aspect ratio (Table 3). If the mechanism responsible for GSPO is stress-driven mass transfer, this indicates that the differential stress is rather constant throughout the outcrop during reaction even though the orientation of the main stress components significantly varies at the centimetre scale.

The Dahmköhler number can be calculated with the fluid composition at the equilibrium, the reaction rate, the grain size, the diffusion coefficient and the aqueous film thickness (equation 5). There are some uncertainties associated with these parameters, in particular regarding the reaction rate which can vary over several orders of magnitude (see above). Taking into account these uncertainties, $D a_{\alpha}$ is above 1 at $\mathrm{T}>300{ }^{\circ} \mathrm{C}$ for the muscovite + quartz $<=>$ andalusite + sanidine $+\mathrm{H}_{2} \mathrm{O}$ reaction, except near the reaction line (Schramke et al., 1987) (Figure 4).

The acquisition of GSPO is not expected from numerical modelling at high $D a_{\alpha}$, that is in most of the investigated stress-temperature domain except near the reaction line (Figure 6). The dissolution-precipitation process is indeed controlled by diffusion in most of the stress-temperature domain. This implies that mass transfer between the faces is slow compared to reaction, leading to a precipitation of the secondary phases where the primary phases are dissolved. Thus, the lack of GSPO in rocks does not necessary indicate low stresses but rather suggests that reaction took place at high $D a_{\alpha}$, in far from the equilibrium conditions. Interestingly, rocks reacting in these conditions (e.g. hydrothermal alteration, contact metamorphism) do not generally display GSPO (Roselle et al., 1997; Gerdes et al., 1999). Hydrothermal alteration of peridotite at mid-ocean ridges forms rocks with a mesh texture without GSPO (Malvoisin et al., 2017). Such a reaction occurs in environments where stresses can be high as expected near detachment faults along which mantle rocks are exhumed (Olive \& Behn, 2014). Examples of reaction in far from the equilibrium conditions also exist during regional metamorphism. Moore et al. (2019) describe a primary mineralogical assemblage out of equilibrium reacting to form two different secondary mineral assemblages with one stable at higher pressure (A1) than the other (A2). A1 and A2 form under different orientations and have a similar thickness, leading to a limited GSPO. This indicates reaction at high $D a_{\alpha}$, which is consistent with the high differential stress of $0.2 \mathrm{GPa}$ calculated in Moore et al. (2019) (Figures $4 \mathrm{~A}$ and B).

Low $D a_{\alpha}$ can only be reached at low temperature $\left(\mathrm{T}<150{ }^{\circ} \mathrm{C}\right)$ or near thermodynamic equilibrium where reaction rates significantly decrease (Figure 4). Figure 6 indicates that GSPO can only be formed at low $D a_{\alpha}$. Diffusion indeed proceeds faster than 
reaction, allowing mass to be transported from one face to the other before precipitation. The metasediments of the Nufenen pass area continuously dehydrate during the prograde path in Barrovian metamorphism. At the same time, temperature increases leading to the overstepping of metamorphic reactions. This overstepping is limited since the rock rapidly reacts by a dissolution-precipitation process in the presence of fluids. As a result, prograde metamorphic reactions are thought to take place close to the equilibrium line (Wood \& Walther, 1983). When fluid is no longer present, the reaction stops leaving a mineralogical assemblage which can be used to retrieve the pressure-temperature conditions of metamorphism (Spear, 1993). Plagioclase and garnet in the metasediments of the Nufenen pass area precipitate during or after the main foliation event (D2), that is close to the peak metamorphism conditions (Klaper \& Bucher-Nurminen, 1987). They have thus undergone prograde metamorphism in the presence of fluid during the Alpine collision. We thus interpret GSPO in these samples as the result of replacement under stress near thermodynamic equilibrium. This interpretation is consistent with the results of numerical modelling provided here, showing that the distance from the equilibrium is the key parameter controlling the acquisition of GSPO in rocks.

The acquisition of a GSPO during dissolution-precipitation requires the presence of fluid serving as a transport medium for the dissolved minerals. GSPO is observed here in volatile-rich rocks (Bestmann et al., 2004; Imon et al., 2004; Wassmann et al., 2011; Stokes et al., 2012; Bial \& Trepmann, 2013; Wassmann \& Stöckhert, 2013a) and could be used as a marker for fluid presence during metamorphism. In addition, our numerical simulations clearly show that GSPO can only be formed near thermodynamic equilibrium. This suggests that GSPO could be used to probe the distance from the equilibrium during metamorphism. The distance from the equilibrium plays a key role on the kinetics of reaction (Lasaga, 2014) but also, as shown below, on the barometric record during metamorphism.

\subsection{Pressure controlling metamorphic reactions}

Determining the pressure of metamorphic reactions is crucial for interpreting observations in natural samples, thermodynamic calculations and numerical models (Moulas et al., 2019). It serves as a basis in the metamorphic petrology community to reconstruct the geodynamic history of the rocks collected in the field (Spear, 1993). In the presence of fluid, experiments (Llana-Fúnez et al., 2012), theoretical studies (Dahlen, 1992) and field data (Holdaway \& Goodge, 1990) suggest that fluid pressure is the relevant pressure for determining thermodynamic equilibrium. Fluid pressure in the aqueous film varies at grain boundary due to interactions with solid surfaces (Israelachvili, 1992). It is equal to the normal stress in thin fluid films leading to strong pressure gradients at the micrometre scale between differently oriented mineral surfaces (Gratier et al., 2013). Moore et al. (2019) document an orientation dependence for precipitation at grain boundary during metamorphism. Wheeler (2014) proposes to calculate the affinity between differently oriented grain boundaries (reaction pathway) to estimate the effect of stress on thermodynamic equilibrium. Mineral stability fields shift by several hundreds of megapascals with this approach. However, Fletcher (2015) indicates that one cannot freely select a reaction pathway without taking into account reaction kinetics and diffusion. The model proposed here considers these two processes and can thus be used to estimate the effect of stress on pressure record during metamorphism.

The effect of stress on reaction can first be evaluated by trying to conceptually reproduce the approach of Wheeler (2014) with our model. Wheeler (2014) considers an incongruent pressure solution pathway to estimate the displacement of reaction line with stress. This is equivalent to consider that dissolution and precipitation occur in the aqueous film normal to $\sigma_{1}$ and $\sigma_{3}$, respectively (low $D a_{\alpha}$ ). The reaction line is defined as the zero chemical affinity curve $\left(A_{t, 1,3}=0\right.$ or $c_{e, r, 1}=c_{e, p, 3}$ with our formalism). By definition, the dissolving phases have a higher solubility than the precipitating phases at the 


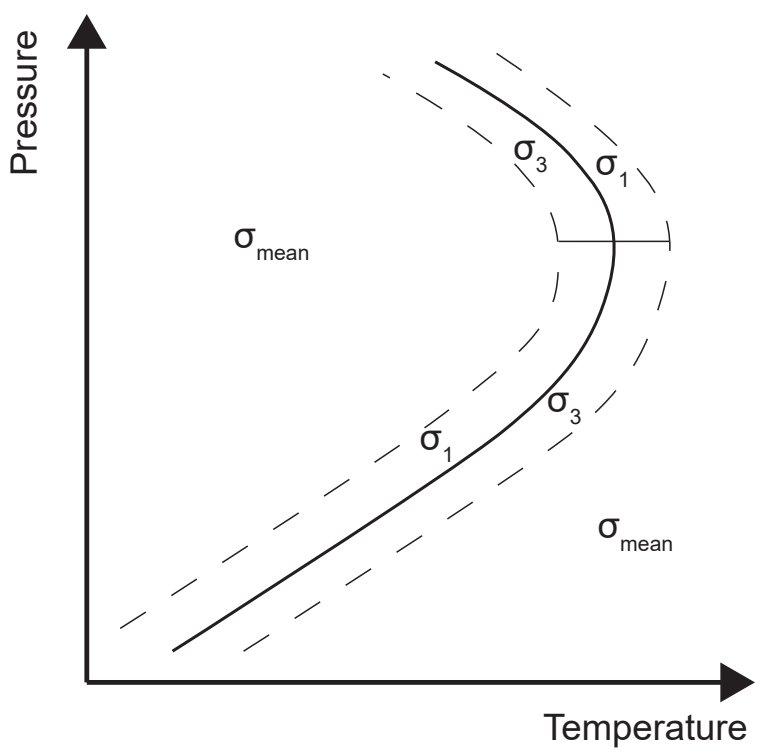

Figure 12. Sketch showing the thermodynamic pressure for metamorphic reactions under stress in a pressure-temperature domain. The plain line is the reaction line where equilibrium between reactant and products is achieved. Far from the equilibrium, the thermodynamic pressure is the mean stress $\left(\sigma_{\text {mean }}\right)$. Near the equilibrium, the thermodynamic pressure depends on the total volume change during reaction. It is $\sigma_{1}$ for $\Delta_{r} V<0$ and $\sigma_{3}$ for $\Delta_{r} V>0$.

same stress, so that $c_{e, r, 1}>c_{e, p, 1}$ and $c_{e, r, 3}>c_{e, p, 3}$. Moreover, solubilities always increase with pressure except near the critical point of water leading to $c_{e, r, 1}>c_{e, r, 3}$ and $c_{e, p, 1}>c_{e, p, 3}$. Combining these four latter inegalities lead to $c_{e, r, 1}>c_{e, p, 3}$, which is not compatible with the condition for zero chemical affinity. As a result, the incongruent pressure solution pathway used in Wheeler (2014) cannot be reproduced with our pressure solution model and pressure solution is thus not expected to significantly modify thermodynamic equilibrium. The only way to reproduce Wheeler (2014)'s approach is to consider that dissolution and precipitation occur in the aqueous film normal to $\sigma_{3}$ and $\sigma_{1}$, respectively $\left(c_{e, p, 1}=c_{e, r, 3}\right)$. This requires a mechanism generating a large supersaturation under $\sigma_{3}$ before transport and precipitation under $\sigma_{1}$. Such a mechanism is known as force of crystallisation (Steiger, 2005).

The model proposed here also provides a way to quantitatively estimate the effect of stress on equilibrium. Mass transfer between differently oriented grain surfaces can only occur at low $D a_{\alpha}$ (fast diffusion compared to reaction). The estimates of $D a_{\alpha}$ in Figure 4 are high except near the reaction line. Moreover, the reaction rate does not depend on stress at high $A_{t, \alpha, \beta}$ (equation 1). Differential stress is thus not expected to have an effect on thermodynamics in far from the equilibrium conditions (Figure 12). The numerical simulations performed here indicate that, near the equilibrium, reaction is affected by differential stress. $\sigma_{1}$ controls the reaction if $A_{t, \alpha, \beta}$ increases with pressure $\left(\Delta_{r} V<\right.$ $0) . \sigma_{3}$ controls the reaction otherwise $\left(\Delta_{r} V>0\right)$. These results are in agreement with the experiments performed by Richter et al. (2016), showing that the quartz to coesite transition $\left(\Delta_{r} V<0\right)$ depends on $\sigma_{1}$. Thermodynamic equilibrium recorded in mineralogical assemblages is thus strongly dependent on the relationship between reaction rate and $A_{t, \alpha, \beta}$. 


\section{Conclusion}

We propose here a model for pressure solution and dissolution-precipitation creeps. This model provides revised deformation mechanism maps for pressure solution. The previous deformation mechanism maps were not incorporating the effect of concentration changes in the aqueous film on reaction rate. We show the critical role of this dependency for estimating strain rates. We also propose new deformation mechanism maps and creep laws for dissolution-precipitation creep. Dissolution-precipitation creep is the main deformation mechanism in the Earth's crust provided that fluid is available and disequilibrium is achieved. The refinement of these deformation mechanism maps requires a detailed investigation of the dependence of reaction rate on pressure and water activity in thin fluid films. We also use numerical modelling to gain insights on the acquisition of GSPO during metamorphism and the pressure controlling metamorphic reactions. We show here that the distance from the equilibrium plays a key role for these two topics. The model is indeed controlled by diffusion in far from the equilibrium conditions, leading to limited mass transfer between the reacting mineral faces. As a result, GSPO does not develop and the effect of stress on thermodynamic pressure is small. In close from the equilibrium conditions, significant differences in reaction rate occur between the mineral faces, leading to a control of the reaction by $\sigma_{1}$ or $\sigma_{3}$. Moreover, the mineral grains change of shape and a GSPO is formed, in agreement with observations in samples from the Nufenen pass area. These results can serve as a basis to interpret GSPO and barometric record in metamorphic rocks.

\section{Appendix A Fit of the experiments of quartz compaction}

We determined $k_{r}$ by fitting with equation 18 the dataset of Niemeijer et al. (2002) for quartz grains compaction in pure water under stresses ranging from 50 to $150 \mathrm{MPa}$ and at temperature comprised between 400 and $600{ }^{\circ} \mathrm{C}$. Strain rate data are reproduced from their figure 4.

$k_{\text {rbulk }}$ ranges from $3.3 \cdot 10^{-6} \mathrm{~mol} . \mathrm{m}^{-2} . \mathrm{s}^{-1}$ at $400{ }^{\circ} \mathrm{C}$ to $1.4 \cdot 10^{-4} \mathrm{~mol} . \mathrm{m}^{-2} . \mathrm{s}^{-1}$ at 600 ${ }^{\circ} \mathrm{C}$ (Tester et al., 1994). The grain sizes are given in their Table 1. The experiments are loaded with sands and the grain contacts thus evolve during compaction. To take into account grain contact evolution, a stress concentration factor depending on porosity $(B(\phi))$ is introduced in the equations in front of the $\left(\sigma_{\alpha}-P_{f, 0}\right)$ term (Dewers \& Hajash, 1995). This factor theoretically tends towards infinity at the beginning of the compaction even though a small elastic distortion occurs leading to finite grain contact (X. Zhang et al., 2010). $B$ is modelled here by using a body centered cubic packing of spherical grains for which:

$$
B(\phi)=\frac{d(\phi)^{2}}{\pi\left(\left(\frac{L}{2}\right)^{2}-\left(\frac{d(\phi)}{2}\right)^{2}\right)}
$$
solving:

where $d$ is the diameter of the grain-to-grain contact determined by numerically

$$
\frac{8}{3} \pi\left(\frac{L}{2}\right)^{3}-\frac{4}{3} \pi(L-d)^{2}\left(L+\frac{d}{2}\right)-(1-\phi)\left(\frac{2 d}{\sqrt{3}}\right)^{3}=0
$$

$B$ is approximately 40 for a ratio between actual porosity and initial porosity of 0.9. This corresponds to an effective pressure of $4 \mathrm{GPa}$ at grain contact for an effective pressure of $100 \mathrm{MPa}$ applied on the sample. The reaction rate constant theoretically varies with pressure as (Schott et al., 2009): 


\begin{tabular}{|c|c|c|}
\hline Symbol & Definition & Unit \\
\hline$r$ & Subscript referring to the dissolving phases & \\
\hline$p$ & Subscript referring to the precipitating phases & \\
\hline$\sigma_{\alpha}$ & Stress component $\alpha$ with $\alpha=1,2$ or 3 and $\sigma_{1}>\sigma_{2}>\sigma_{3}$ & $P a$ \\
\hline$P_{f, 0}$ & Pore pressure & $P a$ \\
\hline $\overrightarrow{x_{\alpha}}$ & Axis vector parallel to $\sigma_{\alpha}$ & $\mathrm{m}$ \\
\hline$\dot{\xi}_{\{r, p\}, \alpha}$ & Reaction rate in the aqueous film normal to $\overrightarrow{x_{\alpha}}$ & mol.s $s^{-1}$ \\
\hline$k_{\{r, p\}}$ & Reaction rate constant & mol. $m^{-2} . s^{-1}$ \\
\hline$k_{m}$ & Mean reaction rate constant defined below equation 9 & mol. $m^{-2} \cdot s^{-1}$ \\
\hline$k_{\text {rbulk }}$ & Reaction rate constant in the bulk fluid & mol. $m^{-2} \cdot s^{-1}$ \\
\hline$a_{\alpha}$ & Activity of dissolved aqueous species in the aqueous film normal to $\overrightarrow{x_{\alpha}}$ & none \\
\hline$a_{e,\{r, p\} \alpha}$ & Activity at the equilibrium of dissolved aqueous species in the film normal to $\overrightarrow{x_{\alpha}}$ & none \\
\hline$c_{\alpha}$ & Concentration of dissolved aqueous species in the aqueous film normal to $\overrightarrow{x_{\alpha}}$ & mol. $m^{-3}$ \\
\hline$c_{e,\{r, p\} \alpha}$ & $\begin{array}{l}\text { Concentration at the equilibrium of dissolved aqueous species in the aqueous film } \\
\text { normal to } \overrightarrow{x_{\alpha}}\end{array}$ & mol.m $m^{-3}$ \\
\hline$c_{0}$ & Concentration of dissolved aqueous species in the pores & mol. $m^{-3}$ \\
\hline$c_{e,\{r, p\}, 0}$ & Concentration at the equilibrium of dissolved aqueous species in the pores & mol. $m^{-3}$ \\
\hline$c_{b, \alpha}$ & $\begin{array}{l}\text { Concentration when balance between the amounts of dissolving and precipitating } \\
\text { minerals in the aqueous film normal to } \overrightarrow{x_{\alpha}} \text {. Defined below equation } 4 \text {. }\end{array}$ & mol. $m^{-3}$ \\
\hline$D$ & Diffusion coefficient in the aqueous fluid film & $m^{2} \cdot s^{-1}$ \\
\hline$S_{\{r, p\}, \alpha}$ & Reactive surface area in one aqueous film normal to $\overrightarrow{x_{\alpha}}$ & $m^{2}$ \\
\hline$S_{0,\{r, p\}}$ & Reactive surface area in one pore & $m^{2}$ \\
\hline$w$ & Thickness of the aqueous film & $m$ \\
\hline$x$ & Length along the grain boundary in 1D & $m$ \\
\hline$L$ & Length of the grain boundary in 1D & $m$ \\
\hline$d$ & Diameter of the grain-to-grain contact defined in equation A2 & $m$ \\
\hline$D a_{\alpha}$ & Damköhler number in the aqueous film normal to $\overrightarrow{x_{\alpha}}$. Defined in equation 5 . & none \\
\hline$D a_{0}$ & Damköhler number in the pores. Defined below equation 7 . & none \\
\hline$V_{\{r, p\}}$ & Molar volume & $m^{3} \cdot m o l^{-1}$ \\
\hline$\Delta_{r} V$ & Change in volume during reaction $\left(V_{p}-V_{r}\right)$ & $m^{3} \cdot m o l^{-1}$ \\
\hline$V_{0}$ & Volume of one pore & $m^{3}$ \\
\hline$\Delta V^{*}$ & Activation volume used in equation A3 & $m^{3} \cdot m o l^{-1}$ \\
\hline$\phi$ & Porosity during compaction experiments & none \\
\hline$\phi_{0}$ & Initial porosity during compaction experiments & none \\
\hline$\mu_{f,\{r, p\}, \alpha}$ & Chemical potential of the mineralogical components dissolved in the fluid & J.mol ${ }^{-1}$ \\
\hline$\mu_{s,\{r, p\}, \alpha}$ & Chemical potential of the solid mineralogical assemblage & J.mol ${ }^{-1}$ \\
\hline$A_{\{r, p\}, \alpha}$ & $\begin{array}{l}\text { Chemical affinity of the dissolution or precipitation reactions in the aqueous film } \\
\text { normal to } \overrightarrow{x_{\alpha}}\left(\mu_{s,\{r, p\}, \alpha}-\mu_{f,\{r, p\}, \alpha}\right)\end{array}$ & J.mol ${ }^{-1}$ \\
\hline$A_{t, \alpha, \beta}$ & Chemical affinity of the replacement reaction $\left(\mu_{s, r, \alpha}-\mu_{s, p, \beta}\right)$ & J.mol \\
\hline$R$ & Gas constant & $J . K^{-1} \cdot \mathrm{mol}^{-1}$ \\
\hline$T$ & Temperature & $K$ \\
\hline$\dot{\epsilon_{\alpha}}$ & Strain rate in direction $\overrightarrow{x_{\alpha}}$ & $s^{-1}$ \\
\hline$\dot{\epsilon_{\alpha V}}$ & Strain rate in direction $\overrightarrow{x_{\alpha}}$ when control by volume change during reaction & $s^{-1}$ \\
\hline$\dot{\epsilon_{\alpha}}$ & Strain rate in direction $\overrightarrow{x_{\alpha}}$ when control by diffusion & $s^{-1}$ \\
\hline$\dot{\epsilon_{\alpha R}}$ & Strain rate in direction $\overrightarrow{x_{\alpha}}$ when control by reaction & $s^{-1}$ \\
\hline$\dot{\epsilon_{\alpha S}}$ & Strain rate in direction $\overrightarrow{x_{\alpha}}$ derived in a similar way to Rutter (1976) & $s^{-1}$ \\
\hline$\epsilon_{\text {dis }}$ & Strain rate for dislocation creep defined in B1 & $s^{-1}$ \\
\hline$\epsilon_{\text {dif }}$ & Strain rate for diffusion creep defined in $\mathrm{B} 2$ & $s^{-1}$ \\
\hline$B$ & Stress concentration factor defined in equation A1 & none \\
\hline$A$ & Pre-exponential factor in the experimental fit of $k_{r}$ & mol. $m^{-2} \cdot s^{-1}$ \\
\hline$E a$ & Energy of activation in the experimental fit of $k_{r}$ & $J m o l^{-1}$ \\
\hline$A_{\text {dis }}$ & Material parameter for dislocation creep & $P a^{-n} \cdot s^{-1}$ \\
\hline$E a_{d i s}$ & Energy of activation for dislocation creep & J.mol ${ }^{-1}$ \\
\hline$n$ & Stress exponent for dislocation creep & none \\
\hline$f_{H 2 O}$ & Water fugacity for dislocation creep & none \\
\hline$h$ & Water fugacity exponent for dislocation creep & none \\
\hline$A_{d i f}$ & Pre-exponential factor for diffusiößn creep & $m^{2} \cdot P a^{-1} \cdot s^{-1}$ \\
\hline$E a_{d i f}$ & Energy of activation for diffusion creep & $J . \mathrm{mol}^{-1}$ \\
\hline
\end{tabular}

Table 1. Symbols used in the mathematical model 


\begin{tabular}{|c|c|c|}
\hline$D a_{\alpha} \quad D a_{0}$ & 0 & $\infty$ \\
\hline 0 & $\begin{array}{c}c_{0}=\frac{4 \sum_{\alpha}\left(c_{b, \alpha} D a_{\alpha}^{2}\right)+c_{b, 0} D a_{0}^{2}}{4 \sum_{\alpha}\left(D a_{\alpha}^{2}\right)+D a_{0}^{2}} \\
c_{\alpha}=c_{0}\end{array}$ & $\begin{array}{c}c_{0}=c_{b, 0} \\
c_{\alpha}=c_{0}\end{array}$ \\
\hline$\infty$ & $\begin{array}{c}c_{0}=\frac{\sum_{\alpha} c_{b, \alpha} D a_{\alpha}}{\sum_{\alpha} D a_{\alpha}} \\
c=c_{b, \alpha}\end{array}$ & $\begin{aligned} c_{0} & =c_{b, 0} \\
c_{\alpha} & =c_{b, a}\end{aligned}$ \\
\hline
\end{tabular}

Table 2. Borderline cases for $c_{\alpha}$ and $c_{0}$ as a function of the Da numbers in the pore $\left(D a_{0}\right)$ and in the aqueous film $\left(D a_{\alpha}\right)$.

\begin{tabular}{lcccccccccc}
\hline Sample & Porphyroblast & S1(field) & $n_{i l m}$ & $\mathrm{~F}$ (ilmenite) & $n_{p b}$ & MEA & MSP & F/MSP $\left({ }^{\circ}\right)$ & F $/$ MEA $\left(^{\circ}\right)$ & Aspect ratio \\
\hline LB_2018_1 & Plagioclase & $348 / 73$ & 1126 & $140 / 74$ & 32 & $156 / 41$ & $5 / 62$ & 62 & 1 & $2.0 \pm 0.4$ \\
\hline LB_2018_2 & Plagioclase & $348 / 73$ & 1417 & $150 / 90$ & 40 & $181 / 66$ & $169 / 86$ & 20 & 12 & $2.2 \pm 0.4$ \\
\hline LB_2018_3 & Plagioclase & $337 / 81$ & 1182 & $112 / 85$ & 40 & $266 / 67$ & $222 / 70$ & 72 & 5 & $2.4 \pm 0.6$ \\
\hline LB_2018_3_2 & Plagioclase & $337 / 81$ & 814 & $304 / 85$ & 25 & $326 / 79$ & $216 / 78$ & 87 & 1 & $2.0 \pm 0.5$ \\
\hline LB_2018_4 & Plagioclase & $138 / 89$ & 839 & $279 / 87$ & 13 & $270 / 59$ & $247 / 81$ & 32 & 7 & $2.3 \pm 0.7$ \\
\hline LB_2018_5 & Plagioclase & $138 / 89$ & 1539 & $108 / 90$ & 17 & $282 / 86$ & $227 / 86$ & 61 & 0 & $2.4 \pm 0.7$ \\
\hline LB_2018_11 & Plagioclase & $131 / 89$ & 991 & $312 / 83$ & 42 & $350 / 68$ & $325 / 80$ & 13 & 7 & $2.6 \pm 0.4$ \\
\hline LB_2018_6 & Garnet & $352 / 78$ & 1822 & $356 / 76$ & 75 & $330 / 76$ & $158 / 88$ & 24 & 19 & $1.8 \pm 0.4$ \\
\hline LB_2018_7 & Garnet & $352 / 81$ & 1480 & $352 / 83$ & 67 & $207 / 63$ & $169 / 73$ & 25 & 22 & $1.6 \pm 0.3$ \\
\hline LB_2018_7_2 & Garnet & $352 / 81$ & 1471 & $354 / 84$ & 96 & $236 / 77$ & $158 / 77$ & 25 & 18 & $1.8 \pm 0.4$ \\
\hline LB_2018_8 & Garnet & $350 / 79$ & 1374 & $342 / 82$ & 40 & $200 / 79$ & $165 / 84$ & 15 & 15 & $2.1 \pm 0.5$ \\
\hline LB_2018_9 & Garnet & $350 / 79$ & 1364 & $348 / 79$ & 40 & $197 / 80$ & $171 / 85$ & 16 & 15 & $2.3 \pm 0.9$ \\
\hline LB_2018_10 & Garnet & NA* & 654 & $126 / 30^{*}$ & 65 & $132 / 11^{*}$ & $5 / 15 *$ & 39 & 7 & $1.7 \pm 0.2$ \\
\hline
\end{tabular}

Table 3. Results of the statistical analysis for porphyroblasts orientation (values are given as Azimuth/Dip). S1(field), F(ilmenite), MEA and MSP refer to the trend/plunge of the Schistosity measured in the field, the Foliation measured with the ilmenite main shortening plane, the Mean main Elongation Axis of the porphyblast and the Mean main Shortening Plane of the porphyroblast, respectively. The mean orientations are determined with Bingham distribution. $n_{i l m}$ and $n_{p b}$ are the number of analyzed ilmenite and porphyroblast grains, respectively. F/MSP is the angle between the foliation orientation measured with ilmenite and the main shortening axis. F/MEA is the angle between the foliation orientation measured with ilmenite and the main elongation axis. *: sample LB_2018_10 was not collected in place and orientations are thus given relative to an arbitrary plane chosen as the planar bottom of the core. 


$$
\left.\frac{\partial \ln k_{r}}{\partial P}\right|_{T}=-\frac{\Delta V^{*}\left(\sigma_{\alpha}-P_{f, 0}\right)}{R T}
$$

where $\Delta V^{*}$ is the volume of activation (volume of the activated complex minus volume of the reactant). $\Delta V^{*}$ is approximately $-1.5 \mathrm{~cm}^{3} \cdot \mathrm{mol}^{-1}$ at $200-300^{\circ} \mathrm{C}$ and several tens of megapascals (R. Zhang et al., 2015). Using this volume of activation, the reaction rate of quartz dissolution should increase with pressure by a factor $\sim 1.7, \sim 13$ and $\sim 3.10^{4}$ for stresses of $200 \mathrm{MPa}, 1 \mathrm{GPa}$ and $4 \mathrm{GPa}$, respectively. Equation $\mathrm{A} 3$ allows to correct reaction progress for the effect of pressure.

\section{Appendix B Dislocation and diffusion creeps for the deformation mech- anism maps}

Dislocation creep is modelled following Tokle et al. (2019) as:

$$
\epsilon_{\dot{d i s}}=A_{d i s}\left(\sigma_{\alpha}-P_{f, 0}\right)^{n} f_{H 2 O}^{h} \exp \left(-\frac{E a_{d i s}}{R T}\right)
$$

with $A_{d i s}$ a material parameter, $n$ is a stress exponent, $f_{H 2 O}$ is the water fugacity, $h$ is the water fugacity exponent and $E a_{d i s}$ is the activation energy for dislocation. We used the parameters from the extrapolated fits of Tokle et al. (2019) (their Table 1). We take into account the change of stress exponent in the flow law (from $n=4$ to $n=$ 3 ) when stress increases. We use a linear transition from one flow law to the other between 100 and $400 \mathrm{MPa}$. Water fugacity is calculated with the Pitzer and Sterner (1994)'s equation of state.

Diffusion creep is modelled following Rutter and Brodie (2004):

$$
\epsilon_{d i f}=\frac{A_{d i f}\left(\sigma_{\alpha}-P_{f, 0}\right) \exp \left(-\frac{E a_{d i f}}{R T}\right)}{L^{2}}
$$

where $A_{d i s}$ is a material parameter and $E a_{d i f}$ is the activation energy for diffusion creep.

\section{Appendix C Creep law for pressure solution with a derivation sim- ilar to Rutter (1976)}

We derive in the following a creep law in the diffusion-controlled case in a similar way to Rutter (1976) but with the formalism and the geometry adopted here. The two main assumptions used in Rutter (1976) are that the reaction rate is constant $\left(\dot{\xi}_{r, \alpha}=\right.$ $\left.k_{r} S_{r, \alpha}\right)$ and that thermodynamic equilibrium is achieved in the thin aqueous film $\left(c_{\alpha}=\right.$ $\left.c_{e, r, \alpha}\right)$.

The assumption of constant reaction rate simplifies equation 2 at steady state in one dimension as:

$$
D \frac{\partial^{2} c_{\alpha}}{\partial x^{2}}+\frac{k_{r}}{w}=0
$$

which can be solved to express $c_{\alpha}$ as a parabolic function:

$$
c_{\alpha}(x)=c_{0}+c_{e, r, \alpha} \frac{D a_{\alpha}^{2}}{2}\left(\frac{x}{L}-\left(\frac{x}{L}\right)^{2}\right)
$$


An other equation for concentration is generally considered by assuming the achievement of thermodynamic equilibrium in the aqueous film by integrating equation 10 over the aqueous film length (equation 3 from Rutter (1976)):

$$
\int_{0}^{L} c_{\alpha}(x) d x=c_{e, r, \alpha} L
$$

Equations $\mathrm{C} 2$ and $\mathrm{C} 3$ deal with the same single variable, $c_{\alpha}(x)$. They are generally combined to express one of the model parameters (usually the reaction rate, $k_{r}$ ) as a function of the others:

$$
k_{r}=12 \frac{c_{e, r, 0} D w}{L^{2}}\left(\exp \left(\frac{\left(\sigma_{\alpha}-P_{f, 0}\right) V_{r}}{R T}\right)-1\right)
$$

Introducing the derivative of equation $\mathrm{C} 2$ at $x=0$ into equation 13 and replacing $k_{r}$ with equation $\mathrm{C} 4$ provide the following equation for strain rate :

$$
\dot{\epsilon_{\alpha S}}=-\frac{24 c_{e, r, 0} D w V_{r}}{L^{3}}\left(1-\exp \left(\frac{\left(\sigma_{\alpha}-P_{f, 0}\right) V_{r}}{R T}\right)\right) \approx \frac{24 c_{e, r, 0} D w V_{r}^{2}\left(\sigma_{\alpha}-P_{f, 0}\right)}{R T L^{3}}
$$

\section{Acknowledgments}

B.M. acknowledges support from the Swiss National Science Foundation (Grant No. PZ00P2_168083). The mathematical model can be reproduced following derivations specified in the text of the paper. We thank J.-P. Gratier and an anonymous referee for reviews, W. Behr for editorial handling, and J. Wheeler and J. Platt for discussions.

\section{References from the Supporting information}

(Lanari et al., 2014)

\section{References}

Álvarez-Valero, A. M., Cesare, B., \& Kriegsman, L. M. (2005, feb). Formation of elliptical garnet in a metapelitic enclave by melt-assisted dissolution and reprecipitation. Journal of Metamorphic Geology, 23(2), 65-74. Retrieved from http://doi.wiley.com/10.1111/j.1525-1314.2005.00562.x doi: 10.1111/j.1525-1314.2005.00562.x

Arvidson, R. S., Beig, M. S., \& Luttge, A. ～(2004, jan). Single-crystal plagioclase feldspar dissolution rates measured by vertical scanning interferometry. American Mineralogist, 89(1), 51-56. Retrieved from https:// pubs.geoscienceworld.org/msa/ammin/article-pdf/89/1/51/3607496/ $07\left\{\backslash_{-}\right\} 1246$ Arvidson.pdfhttps://pubs .geoscienceworld.org/ammin/ article/89/1/51-56/44046 doi: 10.2138/am-2004-0107

Awad, A., Koster van Groos, A., \& Guggenheim, S. (2000, may). Forsteritic olivine: effect of crystallographic direction on dissolution kinetics. Geochimica et Cosmochimica Acta, 64(10), 1765-1772. Retrieved from https:// www.sciencedirect.com/science/article/pii/S0016703799004421http:// linkinghub.elsevier.com/retrieve/pii/S0016703799004421 doi: 10.1016/S0016-7037(99)00442-1

Bell, T. H., \& Rubenach, M. J. (1983). Sequential porphyroblast growth and crenulation cleavage development during progressive deformation. Tectonophysics, 92(1-3), 171-194. Retrieved from https://www.researchgate.net/ publication/248240725 doi: 10.1016/0040-1951(83)90089-6 
Bell, T. H., Rubenach, M. J., \& Fleming, P. D. (1986, feb). Porphyroblast nucleation, growth and dissolution in regional metamorphic rocks as a function of deformation partitioning during foliation development. Journal of Metamorphic Geology, 4(1), 37-67. Retrieved from http://doi.wiley.com/10.1111/ j.1525-1314.1986.tb00337.x doi: 10.1111/j.1525-1314.1986.tb00337.x

Bestmann, M., Prior, D. J., \& Veltkamp, K. T. (2004, may). Development of single-crystal $\sigma$-shaped quartz porphyroclasts by dissolutionprecipitation creep in a calcite marble shear zone. Journal of Structural Geology, 26(5), 869883. Retrieved from https://linkinghub.elsevier.com/retrieve/pii/ S0191814103001652 doi: $10.1016 / j$ j.jsg.2003.10.003

Bial, J., \& Trepmann, C. A. (2013, oct). The microstructural record of porphyroclasts and matrix of partly serpentinized peridotite mylonites from brittle and crystal-plastic deformation to dissolutionprecipitation creep. Solid Earth, 4 (2), 315-330. Retrieved from www.solid-earth.net/4/315/2013/https:// se.copernicus.org/articles/4/315/2013/ doi: 10.5194/se-4-315-2013

Bons, P. D., \& den Brok, B. (2000, nov). Crystallographic preferred orientation development by dissolution-precipitation creep Journal of Structural Geology, 22(11-12), 1713-1722. Retrieved from https:// www.sciencedirect.com/science/article/pii/S0191814100000754http:// linkinghub.elsevier.com/retrieve/pii/S0191814100000754 doi: 10.1016/S0191-8141(00)00075-4

Brady, J. (1983). Intergranular diffusion in metamorphic rocks. American Journal of Science, 283 A, 181-200. Retrieved from http://www.science.smith.edu/ $\{\sim$ jbrady/Papers/Intergranular $\{\backslash\}$ Diffusion.pdf

Cardozo, N., \& Allmendinger, R. W. $\quad$ (2013, feb). Spherical projections with OSXStereonet. Computers \& Geosciences, 51, 193-205. Retrieved from https://www.sciencedirect.com/science/article/pii/ S0098300412002646https://linkinghub.elsevier.com/retrieve/pii/ S0098300412002646 doi: $10.1016 /$ j.cageo.2012.07.021

Connolly, J. (1997, aug). Devolatilization-generated fluid pressure and deformationpropagated fluid flow during prograde regional metamorphism. Journal of Geophysical Research: Solid Earth, 102(B8), 18149-18173. Retrieved from http://onlinelibrary.wiley.com/doi/10.1029/97JB00731/fullhttp:// doi.wiley.com/10.1029/97JB00731 doi: 10.1029/97JB00731

Connolly, J. $\quad(2005$, jul). Computation of phase equilibria by linear programming: A tool for geodynamic modeling and its application to subduction zone decarbonation. $\quad$ Earth and Planetary Science Letters, 236(1-2), 524541. Retrieved from http://linkinghub.elsevier.com/retrieve/pii/ S0012821X05002839https://linkinghub.elsevier.com/retrieve/pii/ S0012821X05002839 doi: 10.1016/j.epsl.2005.04.033

Dahlen, F. A. (1992, mar). Metamorphism of nonhydrostatically stressed rocks. American Journal of Science, 292(3), 184-198. Retrieved from http:// www. ajsonline.org/content/292/3/184. shorthttp://www. ajsonline.org/ cgi/doi/10.2475/ajs.292.3.184 doi: 10.2475/ajs.292.3.184

de Meer, S., \& Spiers, C. J. (1999). On Mechanisms and Kinetics of Creep by Intergranular Pressure Solution. In Growth, dissolution and pattern formation in geosystems (pp. 345-366). Dordrecht: Springer Netherlands. Retrieved from http://link.springer.com/10.1007/978-94-015-9179-9\{\_\}16 doi: 10.1007/978-94-015-9179-9\{\-\}16

den Brok, S. (1998, oct). Effect of microcracking on pressure-solution strain rate: The Gratz grain-boundary model. Geology, 26(10), 915. Retrieved from https://pubs.geoscienceworld.org/geology/article/26/10/915-918/ 206780 doi: 10.1130/0091-7613(1998)026〈0915:EOMOPS $>2.3 . C O ; 2$

Desarnaud, J., Bonn, D., \& Shahidzadeh, N. (2016, nov). The Pressure induced by salt crystallization in confinement. Scientific Reports, 6(1), 
30856. Retrieved from http://www.nature.com/articles/srep30856 doi: $10.1038 /$ srep30856

Dewers, T., \& Hajash, A.

(1995, jul).

Rate laws for water-assisted compaction and stress-induced water-rock interaction in sandstones.

Journal of Geophysical Research: Solid Earth, 100(B7), 13093-13112. Retrieved from https://agupubs.onlinelibrary.wiley.com/doi/abs/10.1029/ 95JB00912\{\\%\}4010.1002/\{\\%\}28ISSN $\{\backslash \%\} 292169-9356$. MIFF 1 http: // doi.wiley.com/10.1029/95JB00912 doi: 10.1029/95JB00912

Dolejš, D., \& Manning, C. (2011, mar). Thermodynamic Model for Mineral Solubility in Aqueous Fluids: Theory, Calibration and Application to Model Fluid-Flow Systems. In Frontiers in geofluids (Vol. 10, pp. 20-40). John Wiley \& Sons, Ltd (10.1111). Retrieved from http://doi.wiley.com/10.1111/ j.1468-8123.2010.00282.x doi: 10.1002/9781444394900.ch3

Duebendorfer, E. M., \& Frost, B. R. (1988). Retrogressive dissolution of garnet: Effect on garnet-biotite geothermometry. Geology, 16(10), 875. doi: 10.1130/ 0091-7613(1988)016<0875:rdogeo $\rangle$ 2.3.co;2

Durney, D. (1972, feb). Solution-transfer, an Important Geological Deformation Mechanism. Nature, 235(5337), 315-317. Retrieved from http://www. nature .com/articles/235315a0 doi: 10.1038/235315a0

Dysthe, D., Renard, F., Porcheron, F., \& Rousseau, B. (2002, apr). Fluid in mineral interfaces - Molecular simulations of structure and diffusion. Geophysical Research Letters, 29(7), 1109. Retrieved from http://doi.wiley.com/10.1029/ 2001GL013208 doi: 10.1029/2001GL013208

Engelder, T., \& Marshak, S. (1985, jan). Disjunctive cleavage formed at shallow depths in sedimentary rocks. Journal of Structural Geology, 7(3-4), 327343. Retrieved from https://www.sciencedirect.com/science/article/ pii/0191814185900392https://linkinghub.elsevier.com/retrieve/pii/ 0191814185900392 doi: 10.1016/0191-8141(85)90039-2

Eugster, H. P., \& Baumgartner, L. (1987). Mineral solubilities and speciation in supercritical metamorphic fluids. Reviews in Mineralogy and Geochemistry, $17(1), 367-403$.

Fletcher, R. C. (2015). Dramatic effects of stress on metamorphic reactions: COMMENT (Vol. 43) (No. 1). Retrieved from https://www.researchgate.net/ publication/279286857 doi: 10.1130/G36302C.1

Ford, J., \& Wheeler, J. (2004, may). Modelling interface diffusion creep in two-phase materials. Acta Materialia, 52(8), 2365-2376. Retrieved from http://pcwww.liv.ac.uk/johnwh/.https://linkinghub.elsevier.com/ retrieve/pii/S1359645404000527 doi: 10.1016/j.actamat.2004.01.045

Gerdes, M. L., Baumgartner, L. P., \& Valley, J. W. (1999, jun). Stable Isotopic Evidence for Limited Fluid Flow through Dolomitic Marble in the Adamello Contact Aureole, Cima Uzza, Italy. Journal of Petrology, 40(6), 853-872. Retrieved from https://academic.oup.com/petrology/article-lookup/doi/ 10.1093/petroj/40.6.853 doi: $10.1093 /$ petroj/40.6.853

Gratier, J.-P., Dysthe, D. K., \& Renard, F. ～(2013, jan). The Role of Pressure Solution Creep in the Ductility of the Earth's Upper Crust. In Advances in geophysics (Vol. 54, pp. 47-179). Elsevier. Retrieved from https://www.sciencedirect.com/science/article/pii/ B9780123809407000020https://linkinghub.elsevier.com/retrieve/ pii/B9780123809407000020 doi: 10.1016/B978-0-12-380940-7.00002-0

Gratier, J.-P., \& Gamond, J. (1990, jan). Transition between seismic and aseismic deformation in the upper crust. Geological Society, London, Special Publications, 54 (1), 461-473. Retrieved from http://sp.lyellcollection.org/ lookup/doi/10.1144/GSL.SP.1990.054.01.42 doi: 10.1144/GSL.SP.1990 .054 .01 .42

Gratier, J.-P., Guiguet, R., Renard, F., Jenatton, L., \& Bernard, D.

$(2009$, 
mar). A pressure solution creep law for quartz from indentation experiments. Journal of Geophysical Research, 114(B3), B03403. Retrieved from https://agupubs.onlinelibrary.wiley.com/doi/pdf/10.1029/ 2008JB005652http://doi.wiley.com/10.1029/2008JB005652 doi: 10.1029/2008JB005652

Gratier, J.-P., Noiriel, C., \& Renard, F. $\quad$ (2015, oct). Experimental evidence for rock layering development by pressure solution. Geology, 43(10), 871874. Retrieved from http://geology.gsapubs.org/lookup/doi/10.1130/ G36713.1https://pubs.geoscienceworld.org/geology/article/43/10/ 871-874/131696 doi: $10.1130 / \mathrm{G} 36713.1$

Gratier, J.-P., Richard, J., Renard, F., Mittempergher, S., Doan, M.-L., Di Toro, G., ... Boullier, A.-M. $\quad$ (2011, dec). Aseismic sliding of active faults by pressure solution creep: Evidence from the San Andreas Fault Observatory at Depth. Geology, 39(12), 1131-1134. Retrieved from http://pubs.geoscienceworld.org/geology/article/39/12/1131/ 130441/Aseismic-sliding-of-active-faults-by-pressure doi: 10.1130/G32073.1

Gratz, A. J. (1991, sep). Solution-transfer compaction of quartzites: Progress toward a rate law. Geology, 19(9), 901. Retrieved from https:// pubs.geoscienceworld.org/geology/article/19/9/901-904/205352 doi: 10.1130/0091-7613(1991)019<0901:STCOQP $>2.3 . C O ; 2$

Greene, G. W., Kristiansen, K., Meyer, E. E., Boles, J. R., \& Israelachvili, J. N. (2009, may). Role of electrochemical reactions in pressure solution. Geochimica et Cosmochimica Acta, 73(10), 2862-2874. Retrieved from https://www .sciencedirect.com/science/article/pii/S0016703709001008https:// linkinghub.elsevier.com/retrieve/pii/S0016703709001008 doi: 10.1016/j.gca.2009.02.012

Gundersen, E., Renard, F., Dysthe, D. K., Bjørlykke, K., \& Jamtveit, B. $\quad$ (2002, nov). Coupling between pressure solution creep and diffusive mass transport in porous rocks. Journal of Geophysical Research: Solid Earth, 107(B11), ECV 19-1-ECV 19-19. Retrieved from https://agupubs.onlinelibrary.wiley .com/doi/pdf/10.1029/2001JB000287http://doi .wiley.com/10.1029/ 2001JB000287 doi: 10.1029/2001JB000287

Hara, I., Shiota, T., \& Hide, K. (1984). Pressure solution of plagioclase and garnet during Nagahama folding in the Sambagawa belt of Central Shikoku. The Journal of the Geological Society of Japan, 90(1), 33-42. Retrieved from http://joi.jlc.jst.go.jp/JST. Journalarchive/geosoc1893/ 90.33? from=CrossRef doi: $10.5575 /$ geosoc. 90.33

Heald, M. T. (1955). Stylolites in Sandstones. The Journal of Geology, 63(2), 101114. Retrieved from http://www.jstor.org/stable/30080871

Hobbs, B. E., \& Ord, A. (2016, dec). Does non-hydrostatic stress influence the equilibrium of metamorphic reactions? EarthScience Reviews, 163, 190-233. Retrieved from https://reader .elsevier.com/reader/sd/pii/S0012825216302707?token= 4DE6BCEB9BC581341C82674D00865805FB683C4CF38099F5DA33078BDE5E0A1FA40E7D1C8488541FAB0EED45EA linkinghub.elsevier.com/retrieve/pii/S0012825216302707 doi: 10.1016/j.earscirev.2016.08.013

Holdaway, M., \& Goodge, J. (1990). Rock pressure vs. fluid pressure as a controlling influence on mineral stability: an example from New Mexico. American Mineralogist, 75 (9-10), 1043-1058.

Holland, T., \& Powell, R. (2011, apr). An improved and extended internally consistent thermodynamic dataset for phases of petrological interest, involving a new equation of state for solids. Journal of Metamorphic Geology, 29(3),333-383. Retrieved from http://onlinelibrary.wiley.com/doi/ 10.1111/j.1525-1314.2010.00923.x/fullhttp://doi.wiley.com/10.1111/ 
j.1525-1314.2010.00923.x doi: 10.1111/j.1525-1314.2010.00923.x

Imon, R., Okudaira, T., \& Kanagawa, K. (2004, may). Development of shapeand lattice-preferred orientations of amphibole grains during initial cataclastic deformation and subsequent deformation by dissolutionprecipitation creep in amphibolites from the Ryoke metamorphic belt, SW Japan. Journal of Structural Geology, 26(5), 793-805. Retrieved from https://linkinghub.elsevier.com/retrieve/pii/S0191814103001615 doi: $10.1016 /$ j.jsg.2003.09.004

Israelachvili, J. (1992). Intermolecular and Surface Forces. Intermolecular and Surface Forces, 450(2), 1-18.

Kamber, B. (1993). Regional metamorphism and uplift along the southern margin of the Gotthard massif; results from the Nufenenpass area. Schweizerische Mineralogische und Petrographische Mitteilungen, 73(2), 241-257.

Karato, S.-i., Wang, Z., Liu, B., \& Fujino, K. (1995, feb). Plastic deformation of garnets: systematics and implications for the rheology of the mantle transition zone. $\quad$ Earth and Planetary Science Letters, 130(1-4), 13-30. Retrieved from https://www.sciencedirect.com/science/article/pii/ 0012821X9400255Whttps://linkinghub.elsevier.com/retrieve/pii/ 0012821X9400255W doi: 10.1016/0012-821X(94)00255-W

Ketcham, R. A. (2005, aug). Computational methods for quantitative analysis of three-dimensional features in geological specimens. Geosphere, 1(1), 32. Retrieved from https://pubs.geoscienceworld.org/geosphere/article/1/1/ 32-41/31089 doi: 10.1130/GES00001.1

Kilian, R., Heilbronner, R., \& Stünitz, H. (2011, aug). Quartz grain size reduction in a granitoid rock and the transition from dislocation to diffusion creep. Journal of Structural Geology, 33(8), 1265-1284. Retrieved from https://www .sciencedirect.com/science/article/pii/S0191814111000848https:// linkinghub.elsevier.com/retrieve/pii/S0191814111000848 doi: 10.1016/j.jsg.2011.05.004

Klaper, E., \& Bucher-Nurminen, K. (1987, apr). Alpine metamorphism of pelitic schists in the Nufenen Pass area, Lepontine Alps. Journal of Metamorphic Geology, 5(2), 175-195. Retrieved from http://doi.wiley.com/10.1111/j.1525 -1314.1987.tb00378.x doi: 10.1111/j.1525-1314.1987.tb00378.x

Kretz, R. (1966, feb). Interpretation of the shape of mineral grains in metamorphic rocks. Journal of Petrology, 7(1), 68-94. Retrieved from https://academic .oup.com/petrology/article-lookup/doi/10.1093/petrology/7.1.68 doi: 10.1093/petrology/7.1.68

Lamadrid, H. M., Rimstidt, J. D., Schwarzenbach, E. M., Klein, F., Ulrich, S., Dolocan, A., \& Bodnar, R. J. (2017, jul). Effect of water activity on rates of serpentinization of olivine. Nature Communications, 8, 16107. Retrieved from http: //www.nature.com/doifinder/10.1038/ncomms16107 doi: $10.1038 /$ ncomms16107

Lanari, P., Vidal, O., De Andrade, V., Dubacq, B., Lewin, E., Grosch, E. G., \& Schwartz, S. (2014, jan). XMapTools: A MATLABCC-based program for electron microprobe X-ray image processing and geothermobarome-

try. Computers \& Geosciences, 62, 227-240. Retrieved from https://www .sciencedirect.com/science/article/pii/S0098300413002379https:// linkinghub.elsevier.com/retrieve/pii/S0098300413002379 doi: 10.1016/j.cageo.2013.08.010

Lasaga, A. C. (2014). Kinetic Theory in the Earth Sciences. Retrieved from https : //books . google. com/books?hl=fr $\{\backslash \&\} l r=\{\backslash \&\}$ id= 21YABAAAQBAJ $\{\backslash \&\}$ pgis $=1$

Leu, W. (1985). Geologie der Sedimentzüge zwischen Griessee und Passa del Corno (Nufenengebiet, Wallis). Eclogae Geologicae Helvetiae, 78(3), 537-544. Retrieved from https://pascal-francis.inist.fr/vibad/index.php?action= 
getRecordDetail $\{\backslash \&\}$ idt=8465919 doi: $10.5169 /$ seals-165669

Liskay-Nagy, M. (1965). Geologie der Sedimentbedeckung des südwestlichen Gotthard-Massivs im Oberwallis. Eclogae Geologicae Helvetiae, 58, 901965. Retrieved from https://scholar.google.com/scholar?hl=fr $\{\backslash \&\}$ as $\{\backslash$ _\}sdt $=0\{\backslash \%\} 2 \mathrm{C} 5\{\backslash \&\}$ q $=$ Liszkay-Nagy+M+\{\\%\}281965\{\\%\}29+Geologie+der+ Sedimentbedeckung+des+s $\{\backslash$ "u\}\}dwestlichen+Gotthard-Massivs+im+ Oberwallis .+Eclogae+Geologicae+Helvetiae+58\{\\%\}3A901966 . +doi $\{\backslash \%$ \}3A+10.5169\{\\%\}2Fseals $-163285\{\backslash \&\}$ btnG $=$ doi: $10.5169 /$ seals -163285

Llana-Fúnez, S., Wheeler, J., \& Faulkner, D. R. (2012, jul). Metamorphic reaction rate controlled by fluid pressure not confining pressure: implications of dehydration experiments with gypsum. Contributions to Mineralogy and Petrology, 164(1), 69-79. Retrieved from http://link.springer.com/10.1007/ s00410-012-0726-8 doi: 10.1007/s00410-012-0726-8

Malvoisin, B., Brantut, N., \& Kaczmarek, M.-A. (2017, oct). Control of serpentinisation rate by reaction-induced cracking. Earth and Planetary Science Letters, 476, 143-152. Retrieved from https://linkinghub.elsevier.com/retrieve/ pii/S0012821X17304260 doi: 10.1016/j.epsl.2017.07.042

McAleer, R. J., Bish, D. L., Kunk, M. J., Sicard, K. R., Valley, P. M., Walsh, G. J., ... Wintsch, R. P. (2017, jan). Reaction softening by dissolutionprecipitation creep in a retrograde greenschist facies ductile shear zone, New Hampshire, USA. Journal of Metamorphic Geology, 35(1), 95-119. Retrieved from http://doi.wiley.com/10.1111/jmg.12222 doi: 10.1111/jmg.12222

Means, W., \& Paterson, M. (1966). Experiments on preferred orientation of platy minerals. Contributions to Mineralogy and Petrology, 13(2), 108-133. Retrieved from http://link.springer.com/10.1007/BF00518022 doi: 10.1007/ BF00518022

Moore, J., Beinlich, A., Austrheim, H., \& Putnis, A. $\quad$ (2019, feb). Stress orientationdependent reactions during metamorphism. Geology, 47(2), 151-154. Retrieved from https://pubs.geoscienceworld.org/gsa/geology/article/ 47/2/151/568046/Stress-orientationdependent-reactions-during doi: $10.1130 / \mathrm{G} 45632.1$

Moulas, E., Schmalholz, S. M., Podladchikov, Y., Tajčmanová, L., Kostopoulos, D., \& Baumgartner, L. (2019, jan). Relation between mean stress, thermodynamic, and lithostatic pressure. Journal of Metamorphic Geology, 37(1), 1-14. Retrieved from http://doi.wiley.com/10.1111/jmg.12446 doi: $10.1111 /$ jmg. 12446

Niemeijer, A., Spiers, C., \& Bos, B. $\quad$ (2002, feb). Compaction creep of quartz sand at $400-600^{\circ} \mathrm{C}$ : experimental evidence for dissolution-controlled pressure solution. Earth and Planetary Science Letters, 195(3-4), 261-275. Retrieved from https://www.sciencedirect.com/science/article/pii/ S0012821X01005933http://linkinghub.elsevier.com/retrieve/pii/ S0012821X01005933 doi: 10.1016/S0012-821X(01)00593-3

Oelkers, E. H., \& Helgeson, H. C. $\quad$ (1988, jan). Calculation of the thermodynamic and transport properties of aqueous species at high pressures and temperatures: Aqueous tracer diffusion coefficients of ions to $1000 \mathrm{C}$ and $5 \mathrm{~kb}$. Geochimica et Cosmochimica Acta, 52(1), 63-85. Retrieved from https:// wWw.sciencedirect.com/science/article/pii/0016703788900579https:// linkinghub.elsevier.com/retrieve/pii/0016703788900579 doi: 10.1016/0016-7037(88)90057-9

Olive, J. A., \& Behn, M. D. (2014). Rapid rotation of normal faults due to flexural stresses: An explanation for the global distribution of normal fault dips. Journal of Geophysical Research: Solid Earth, 119(4), 3722-3739. Retrieved from https://agupubs.onlinelibrary.wiley.com/doi/pdf/10.1002/ 2013JB010512 doi: 10.1002/2013JB010512

Omlin, S., Malvoisin, B., \& Podladchikov, Y. Y. $\quad$ (2017, sep). Pore Fluid Extrac- 
tion by Reactive Solitary Waves in 3-D. Geophysical Research Letters, 44 (18), 9267-9275. Retrieved from http://doi.wiley.com/10.1002/2017GL074293 doi: 10.1002/2017GL074293

Paterson, M. (1973). Nonhydrostatic thermodynamics and its geologic applications. Reviews of Geophysics, 11(2), 355. Retrieved from http://doi.wiley.com/10 .1029/RG011i002p00355 doi: 10.1029/RG011i002p00355

Pitzer, K. S., \& Sterner, S. M. (1994, aug). Equations of state valid continuously from zero to extreme pressures for $\mathrm{H}_{2} \mathrm{O}$ and $\mathrm{CO}_{2}$. The Journal of Chemical Physics, 101(4), 3111-3116. Retrieved from http://aip.scitation.org/doi/ 10.1063/1.467624 doi: $10.1063 / 1.467624$

Platt, J. P., Xia, H., \& Schmidt, W. L. (2018, dec). Rheology and stress in subduction zones around the aseismic/seismic transition. Progress in Earth and Planetary Science, 5(1), $24 . \quad$ Retrieved from https://doi.org/10.1186/ s40645-018-0183-8https://progearthplanetsci.springeropen.com/ articles/10.1186/s40645-018-0183-8 doi: 10.1186/s40645-018-0183-8

Putnis, A. (2009, jan). Mineral Replacement Reactions. Reviews in Mineralogy and Geochemistry, 70(1), 87-124. Retrieved from http:// rimg.geoscienceworld.org/cgi/doi/10.2138/rmg. 2009.70.3https:// pubs.geoscienceworld.org/rimg/article/70/1/87-124/140824 doi: 10.2138/rmg.2009.70.3

Putnis, A., \& Austrheim, H. (2011, feb). Fluid-Induced Processes: Metasomatism and Metamorphism. In Frontiers in geofluids (Vol. 10, pp. 254-269). Oxford, UK: Wiley-Blackwell. Retrieved from http://doi.wiley.com/ 10.1111/j.1468-8123.2010.00285.xhttp://doi.wiley.com/10.1002/ 9781444394900.ch18 doi: 10.1002/9781444394900.ch18

Putnis, C., Tsukamoto, K., \& Nishimura, Y. (2005, nov). Direct observations of pseudomorphism: Compositional and textural evolution at a fluid-solid interface. American Mineralogist, 90(11-12), 1909-1912. Retrieved from https:// pubs.geoscienceworld.org/ammin/article/90/11-12/1909-1912/44463 doi: $10.2138 / \mathrm{am} .2005 .1990$

Raj, R. (1982, jun). Creep in polycrystalline aggregates by matter transport through a liquid phase. Journal of Geophysical Research: Solid Earth, 87(B6), 47314739. Retrieved from http://doi.wiley.com/10.1029/JB087iB06p04731 doi: 10.1029/JB087iB06p04731

Raufaste, C., Jamtveit, B., John, T., Meakin, P., \& Dysthe, D. K. (2011, may). The mechanism of porosity formation during solvent-mediated phase transformations. Proceedings of the Royal Society A: Mathematical, Physical and Engineering Sciences, 467(2129), 1408-1426. Retrieved from http:// arxiv.org/abs/1006.3649http://rspa.royalsocietypublishing.org/cgi/ doi/10.1098/rspa.2010.0469 doi: 10.1098/rspa.2010.0469

Renard, F., Gratier, J.-P., \& Jamtveit, B. (2000, oct). Kinetics of cracksealing, intergranular pressure solution, and compaction around active faults. Journal of Structural Geology, 22(10), 1395-1407. Retrieved from https://linkinghub.elsevier.com/retrieve/pii/S019181410000064X doi: 10.1016/S0191-8141(00)00064-X

Renard, F., Ortoleva, P., \& Gratier, J. P. $\quad$ (1997, oct). Pressure solution in sandstones: influence of clays and dependence on temperature and stress. Tectonophysics, 280(3-4), 257-266. Retrieved from https:// www.sciencedirect.com/science/article/pii/S0040195197000395http:// linkinghub.elsevier.com/retrieve/pii/S0040195197000395 doi: 10.1016/S0040-1951(97)00039-5

Revil, A. (2001, may). Pervasive pressure solution transfer in a quartz sand. Journal of Geophysical Research: Solid Earth, 106(B5), 8665-8686. Retrieved from http://doi.wiley.com/10.1029/2000JB900465 doi: 10.1029/2000jb900465

Richter, B., Stünitz, H., \& Heilbronner, R. ～(2016, nov). Stresses and pressures 
at the quartz-to-coesite phase transformation in shear deformation experiments. Journal of Geophysical Research: Solid Earth, 121(11), 8015-8033. Retrieved from https://agupubs.onlinelibrary.wiley.com/doi/pdf/ 10.1002/2016JB013084http://doi.wiley.com/10.1002/2016JB013084 doi: 10.1002/2016JB013084

Rimstidt, J. D. (2015, oct). Rate equations for sodium catalyzed quartz dissolution. Geochimica et Cosmochimica Acta, 167, 195-204. Retrieved from https://www .sciencedirect.com/science/article/pii/S0016703715004743https:// linkinghub.elsevier.com/retrieve/pii/S0016703715004743 doi: 10.1016/j.gca.2015.07.030

Roselle, G. T., Baumgartner, L. P., \& Chapman, J. A. (1997, sep). Nucleationdominated crystallization of forsterite in the Ubehebe Peak contact aureole, California. Geology, 25(9), 823. Retrieved from https://pubs .geoscienceworld.org/geology/article/25/9/823-826/206733 doi 10.1130/0091-7613(1997)025〈0823:NDCOFI $\rangle 2.3 . \mathrm{CO} ; 2$

Rosenberg, C. L., \& Stünitz, H. (2003, mar). Deformation and recrystallization of plagioclase along a temperature gradient: An example from the Bergell tonalite. Journal of Structural Geology, 25(3), 389-408. Retrieved from https://linkinghub.elsevier.com/retrieve/pii/S0191814102000366 doi: 10.1016/S0191-8141(02)00036-6

Rubie, D. C. (1986, sep). The catalysis of mineral reactions by water and restrictions on the presence of aqueous fluid during metamorphism. Mineralogical Magazine, 50(357), 399-415. Retrieved from http://www .minersoc.org/pages/Archive-MM/Volume\{\_\}50/50-357-399. pdfhttps:// www. cambridge.org/core/product/identifier/S0026461X00031923/type/ journal\{\_\}article doi: 10.1180/minmag.1986.050.357.05

Rutter, E. $\quad(1976$, oct). The Kinetics of Rock Deformation by Pressure Solution [and Discussion]. Philosophical Transactions of the Royal Society A: Mathematical, Physical and Engineering Sciences, 283(1312), 203-219. Retrieved from http://rsta.royalsocietypublishing.org/cgi/doi/10.1098/ rsta.1976.0079 doi: 10.1098/rsta.1976.0079

Rutter, E. (1983, sep). Pressure solution in nature, theory and experiment. Journal of the Geological Society, 140(5), 725-740. Retrieved from http://jgs.lyellcollection.org/lookup/doi/10.1144/gsjgs.140.5.0725 doi: $10.1144 /$ gsjgs.140.5.0725

Rutter, E., \& Brodie, K. (2004, nov). Experimental grain size-sensitive flow of hotpressed Brazilian quartz aggregates. Journal of Structural Geology, 26(11), 2011-2023. Retrieved from https://www.sciencedirect.com/science/ article/pii/S0191814104000793https://linkinghub.elsevier.com/ retrieve/pii/S0191814104000793 doi: 10.1016/j.jsg.2004.04.006

Schott, J., Pokrovsky, O., \& Oelkers, E. $\quad$ (2009, jan). The Link Between Mineral Dissolution/Precipitation Kinetics and Solution Chemistry. views in Mineralogy and Geochemistry, 70(1), 207-258. Retrieved from https://pubs.geoscienceworld.org/rimg/article/70/1/207-258/140830 doi: $10.2138 /$ rmg.2009.70.6

Schramke, J., Kerrick, D., \& Lasaga, A. (1987, jun). The reaction muscovite + quartz $=$ andalusite + K-feldspar + water; Part 1, Growth kinetics and mechanism. American Journal of Science, 287(6), 517-559. Retrieved from http://www.ajsonline.org/content/287/6/517.extracthttp:// www.ajsonline.org/cgi/doi/10.2475/ajs.287.6.517 doi: 10.2475/ ajs.287.6.517

Shelley, D. $\quad(1989$, jan $) . \quad$ Plagioclase and quartz preferred orientations in a lowgrade schist: the roles of primary growth and plastic deformation. Journal of Structural Geology, 11(8), 1029-1037. Retrieved from https:// linkinghub.elsevier.com/retrieve/pii/0191814189900539 doi: 
10.1016/0191-8141(89)90053-9

Shigematsu, N., \& Tanaka, H. (2000, jan). Dislocation creep of fine-grained recrystallized plagioclase under low-temperature conditions. Journal of Structural Geology, 22(1), 65-79. Retrieved from https://linkinghub.elsevier.com/ retrieve/pii/S0191814199001327 doi: 10.1016/S0191-8141(99)00132-7

Shimizu, I. (1995, may). Kinetics of pressure solution creep in quartz: theoretical considerations. Tectonophysics, 245(3-4), 121-134. Retrieved from https:// www.sciencedirect.com/science/article/pii/0040195194002307http:// linkinghub.elsevier.com/retrieve/pii/0040195194002307 doi: 10.1016/0040-1951(94)00230-7

Smit, M. A., Scherer, E. E., John, T., \& Janssen, A. (2011, nov). Creep of garnet in eclogite: Mechanisms and implications. Earth and Planetary Science Letters, 311(3-4), 411-419. doi: 10.1016/j.epsl.2011.09.024

Spear, F. S. (1993). Metamorphic phase equilibria and pressure-temperature-time paths (Mineralogi ed.). Mineralogical Society of America. Retrieved from http://www . minsocam.org/msa/Monographs/mono01.html

Steiger, M. (2005, sep). Crystal growth in porous materialsI: The crystallization pressure of large crystals. Journal of Crystal Growth, 282(3-4), 455469. Retrieved from http://linkinghub.elsevier.com/retrieve/pii/ S0022024805005920 doi: 10.1016/j.jcrysgro.2005.05.007

Stipp, M., Stünitz, H., Heilbronner, R., \& Schmid, S. M. $\quad$ (2002, dec). The eastern Tonale fault zone: a natural laboratory' for crystal plastic deformation of quartz over a temperature range from 250 to $700 \mathrm{C}$ Journal of Structural Geology, 24(12), 1861-1884. Retrieved from https://www .sciencedirect.com/science/article/pii/S0191814102000354https:// linkinghub.elsevier.com/retrieve/pii/S0191814102000354 doi: 10.1016/S0191-8141(02)00035-4

Stöckhert, B., Wachmann, M., Küster, M., \& Bimmermann, S. （1999, mar). Low effective viscosity during high pressure metamorphism due to dissolution precipitation creep: the record of HP-LT metamorphic carbonates and siliciclastic rocks from Crete. Tectonophysics, 303(1-4), 299-319. Retrieved from https://www.sciencedirect.com/science/article/pii/ S0040195198002625https://linkinghub.elsevier.com/retrieve/pii/ S0040195198002625 doi: 10.1016/S0040-1951(98)00262-5

Stokes, M. R., Wintsch, R. P., \& Southworth, C. S. (2012, sep). Deformation of amphibolites via dissolution-precipitation creep in the middle and lower crust. Journal of Metamorphic Geology, 30(7), 723-737. Retrieved from http://doi.wiley.com/10.1111/j.1525-1314.2012.00989.x doi: 10.1111/j.1525-1314.2012.00989.x

Stünitz, H., Fitz Gerald, J., \& Tullis, J. （2003, sep). Dislocation generation, slip systems, and dynamic recrystallization in experimentally deformed plagioclase single crystals. Tectonophysics, 372(3-4), 215-233. Retrieved from https://linkinghub.elsevier.com/retrieve/pii/S0040195103002415 doi: 10.1016/S0040-1951(03)00241-5

Sverjensky, D. A., Harrison, B., \& Azzolini, D. (2014). Water in the deep Earth: The dielectric constant and the solubilities of quartz and corundum to 60 $\mathrm{kb}$ and $1200^{\circ} \mathrm{C}$. Geochimica et Cosmochimica Acta, 129, 125-145. Retrieved from http://www.sciencedirect.com/science/article/pii/ S0016703713007151http://dx.doi.org/10.1016/j.gca.2013.12.019 doi: 10.1016/j.gca.2013.12.019

Tester, J. W., Worley, W., Robinson, B. A., Grigsby, C. O., \& Feerer, J. L. (1994, jun). Correlating quartz dissolution kinetics in pure water from 25 to $625^{\circ} \mathrm{C}$. Geochimica et Cosmochimica Acta, 58(11), 2407-2420. Retrieved from https://www.sciencedirect.com/science/article/pii/ 0016703794900205https://linkinghub.elsevier.com/retrieve/pii/ 
0016703794900205 doi: 10.1016/0016-7037(94)90020-5

Tokle, L., Hirth, G., \& Behr, W. (2019, jan). Flow laws and fabric transitions in wet quartzite. Earth and Planetary Science Letters, 505, 152-161. Retrieved from https://www.sciencedirect.com/science/article/pii/ S0012821X18306137https://linkinghub.elsevier.com/retrieve/pii/ S0012821X18306137 doi: 10.1016/j.epsl.2018.10.017

Trepmann, C. A., \& Stöckhert, B. (2003, dec). Quartz microstructures developed during non-steady state plastic flow at rapidly decaying stress and strain rate. Journal of Structural Geology, 25(12), 2035-2051. Retrieved from https://www.sciencedirect.com/science/article/pii/ S0191814103000737https://linkinghub.elsevier.com/retrieve/pii/ S0191814103000737 doi: 10.1016/S0191-8141(03)00073-7

van Noort, R., Spiers, C., \& Peach, C. $\quad$ (2007, mar). Effects of orientation on the diffusive properties of fluid-filled grain boundaries during pressure solution. Physics and Chemistry of Minerals, 34(2), 95-112. Retrieved from http://link.springer.com/10.1007/s00269-006-0131-9 doi: 10.1007/s00269-006-0131-9

van Noort, R., Spiers, C., \& Peach, C. (2011, jul). Structure and properties of loaded silica contacts during pressure solution: impedance spectroscopy measurements under hydrothermal conditions. Physics and Chemistry of Minerals, 38(7), 501-516. Retrieved from http://link.springer.com/10.1007/ s00269-011-0423-6 doi: 10.1007/s00269-011-0423-6

Wassmann, S., \& Stöckhert, B. (2013a, jan). Low stress deformation of garnet by incongruent dissolution precipitation creep. Journal of Structural Geology, 46, 200-219. Retrieved from https://www.sciencedirect.com/science/ article/pii/S0191814112001988https://linkinghub.elsevier.com/ retrieve/pii/S0191814112001988 doi: 10.1016/j.jsg.2012.09.002

Wassmann, S., \& Stöckhert, B. (2013b, nov). Rheology of the plate interface - Dissolution precipitation creep in high pressure metamorphic rocks. Tectonophysics, 608,1-29. Retrieved from https://www. sciencedirect.com/science/ article/pii/S0040195113005982https://linkinghub.elsevier.com/ retrieve/pii/S0040195113005982 doi: 10.1016/j.tecto.2013.09.030

Wassmann, S., Stöckhert, B., \& Trepmann, C. A. (2011, jan). Dissolution precipitation creep versus crystalline plasticity in high-pressure metamorphic serpentinites. Geological Society, London, Special Publications, 360(1), 129-149. Retrieved from https://sp.lyellcollection.org/ content/360/1/129https://sp. lyellcollection.org/content/360/1/129 .abstracthttp://sp. lyellcollection.org/lookup/doi/10.1144/SP360.8 doi: $10.1144 /$ SP 360.8

Wheeler, J. (1992, apr). Importance of pressure solution and coble creep in the deformation of polymineralic rocks. Journal of Geophysical Research, 97(B4), 4579. Retrieved from http://doi.wiley.com/10.1029/91JB02476 doi: 10 $.1029 / 91 J B 02476$

Wheeler, J. (2014, aug). Dramatic effects of stress on metamorphic reactions. Geology, 42(8), 647-650. Retrieved from http://pubs.geoscienceworld.org/ geology/article/42/8/647/131598/Dramatic-effects-of-stress-on -metamorphic doi: 10.1130/G35718.1

Wheeler, J. (2018, may). The effects of stress on reactions in the Earth: Sometimes rather mean, usually normal, always important. Journal of Metamorphic Geology, 36(4), 439-461. Retrieved from http://doi.wiley.com/10.1111/jmg .12299 doi: $10.1111 /$ jmg. 12299

Willis, D. G. (1977, jun). A kinematic model of preferred orientation. Bulletin of the Geological Society of America, 88(6), 883-894. Retrieved from https://pubs .geoscienceworld.org/gsabulletin/article/88/6/883-894/202180 doi: 10.1130/0016-7606(1977)88<883:AKMOPO $\rangle 2.0 . \mathrm{CO} ; 2$ 
Wood, B. J., \& Walther, J. V. (1983). Rates of hydrothermal reactions. Science, 222(4622), 413-5. Retrieved from http://www.sciencemag.org/content/ 222/4622/413. short doi: 10.1126/science.222.4622.413

Worley, W., Tester, J., \& Grigsby, C. (1996, dec). Quartz dissolution kinetics from $100-200^{\circ} \mathrm{C}$ as a function of $\mathrm{pH}$ and ionic strength. AIChE Journal, 42(12), 3442-3457. Retrieved from http://doi.wiley.com/10.1002/aic.690421214 doi: $10.1002 /$ aic. 690421214

Xia, H., \& Platt, J. P. (2017, mar). Structural and rheological evolution of the Laramide subduction channel in southern California. Solid Earth, 8(2), 379403. Retrieved from https://www.solid-earth.net/8/379/2017/ doi: 10 $.5194 / \mathrm{se}-8-379-2017$

Yasuhara, H. (2003, nov). A mechanistic model for compaction of granular aggregates moderated by pressure solution. Journal of Geophysical Research, 108(B11), 2530. Retrieved from http://doi.wiley.com/10.1029/ 2003JB002536 doi: 10.1029/2003JB002536

Zhang, R., Zhang, X., \& Hu, S. (2015, may). Dissolution kinetics of quartz in water at high temperatures across the critical state of water. The Journal of Supercritical Fluids, 100, 58-69. Retrieved from https://www.sciencedirect.com/ science/article/pii/S0896844615000716https://linkinghub.elsevier .com/retrieve/pii/S0896844615000716 doi: 10.1016/j.supflu.2015.02.010

Zhang, X., Spiers, C. J., \& Peach, C. J. (2010, sep). Compaction creep of wet granular calcite by pressure solution at $28^{\circ} \mathrm{C}$ to $150^{\circ} \mathrm{C}$. Journal of Geophysical Research, 115(B9), B09217. Retrieved from http://www.slb.com/services/ industry-challenges/http://doi.wiley.com/10.1029/2008JB005853 doi: 10.1029/2008JB005853 